\title{
Flight Mechanical Challenges of STOL Aircraft Using Active High-Lift
}

\author{
J.H. Diekmann* \\ Deutsches Zentrum für Luft- und Raumfahrt e.V. (DLR), German Aerospace Center, Institute of Flight Systems, \\ 38108 Braunschweig, Germany
}

This paper focuses on the flight mechanical characteristics of an active high-lift supported transport type aircraft. The presented configuration combines a boundary-layer controlled flaps system with the benefits of propeller slipstream deflection. The underlying aerodynamic models and assumptions are provided. The extraordinary flight performances especially at low airspeed will be pointed out, as well as potential weaknesses. Special attention is paid to the unusually strong aerodynamic couplings in the lateral motion. Therefore, flight dynamics characteristics will be presented and their challenges discussed. The key influences are pointed out and an outlook will be given, how to exploit this knowledge for safe and satisfactory aircraft operation and handling.

\begin{tabular}{|c|c|c|}
\hline Alt & Altitude & $\mathrm{m}$ \\
\hline$C$ & Coefficient or derivative & \\
\hline$C_{\mu}$ & Jet momentum coefficient & \\
\hline$f, a_{1}$ & Stall model factors & \\
\hline$F, K$ & Lateral model adjustment factors & \\
\hline$i_{H T P}$ & Incidence angle of the horizontal tailplane & $\circ$ \\
\hline$k_{1}, k_{2}$ & Drag polynomial factors & \\
\hline$l_{\mu}$ & Mean aerodynamic chord & $\mathrm{m}$ \\
\hline$l_{X}$ & Lever arm of the horizontal tailplane & $\mathrm{m}$ \\
\hline$M$ & Mach number & \\
\hline$m, \dot{m}$ & Mass, mass flow & $\mathrm{kg}, \mathrm{kg} / \mathrm{s}$ \\
\hline$P_{\text {eng }}$ & Engine power setting & $\%$ \\
\hline$p, q, r$ & Angular rates & $\% / \mathrm{s}$ \\
\hline$q_{\infty}, \bar{q}$ & Dynamic pressure & $\mathrm{N} / \mathrm{m}$ \\
\hline$S$ & Main wing area & $\mathrm{m}^{2}$ \\
\hline$T$ & Thrust & $\mathrm{N}$ \\
\hline$t$ & Time & S \\
\hline$V$ & Airspeed & $\mathrm{m} / \mathrm{s}$ \\
\hline$v_{j e t}$ & Fluid velocity & $\mathrm{m} / \mathrm{s}$ \\
\hline$x, y, z$ & Aircraft position & $\mathrm{m}$ \\
\hline$\alpha$ & Angle of attack & $\circ$ \\
\hline$\alpha^{\star}$ & Stall onset angle & $\circ$ \\
\hline$\beta$ & Sideslip angle & $\circ$ \\
\hline$\gamma$ & Flight path angle & $\circ$ \\
\hline$\Delta \beta$ & Sideslip angle offset & $\circ$ \\
\hline
\end{tabular}

$\begin{array}{lll}\delta & \text { Deflection angle } & \circ \\ \varepsilon & \text { Downwash angle } \\ \tau & \text { Transport delay } \\ \Phi, \Theta, \Psi & \text { Aircraft attitude angles } \\ \chi & \text { Track angle }\end{array}$




\title{
Subscripts
}

$\begin{array}{ll}\text { App } & \text { Approach airspeed } \\ C_{\mu} & \text { W.r.t. jet momentum coefficient } \\ \text { Comp } & \text { Component } \\ D & \text { Drag } \\ D i & \text { Induced drag } \\ d y n & \text { Dynamic value due to angular rates } \\ F l & \text { Flap } \\ j e t & \text { Jet of the blowing system } \\ L & \text { Lift } \\ l & \text { Rolling moment } \\ \text { lon } & \text { Longitudinal } \\ m & \text { Pitching moment } \\ n & \text { Yawing moment } \\ P G & \text { Prandtl-Glauert Mach number correction } \\ R e f & \text { Reference } \\ \text { Stall } & \text { Stall Coefficient } \\ T \text { AS } & \text { True airspeed } \\ \sim & \text { Look-up table } \\ X & \text { Replacement for force or moment } \\ Y & \text { Side force } \\ \eta & \text { Gradient w.r.t. to elevator deflection }\end{array}$

\author{
Conventions \\ AGARD Advisory Group for Aerospace Research and Development \\ AoA \\ BLC \\ Angle of Attack \\ CFD Computational Fluid Dynamics \\ CS-25 Certification Specification 25 \\ DLR Deutsches Zentrum für Luft- und Raumfahrt (German Aerospace Center) \\ DR Dutch Roll \\ EASA European Aviation Safety Agency \\ FAA Federal Aviation Administration \\ MAC Mean Aerodynamic Chord \\ MTOW Maximum Take-Off Weight \\ NASA National Aeronautics and Space Administration \\ OEI One engine inoperative \\ PH Phugoid \\ PrADO Preliminary Aircraft Design and Optimization [tool] \\ QSRA Quiet Short-Haul Research Aircraft \\ RP25 Moment reference point at the wing-root's quarter chord \\ $\mathrm{SC} \quad$ Super-circulation \\ SFB Sonderforschungsbereich (Collaborative Research Center) \\ SP Short period \\ S Spiral motion \\ STOL Short Take-off and Landing \\ WF Wing/Fuselage
}




\section{Introduction}

In the history of short take-off and landing aircraft (STOL) various technologies and combinations of those have been investigated and put to the test for safe and controllable flight at low airspeeds [1] or even hover. Many of these technologies introduce a significantly increased energy consumption which is in contradiction to the efficiency targets in commercial aviation. In order to achieve an efficient compromise between these apparently opposed targets, the collaborative research center "Sonderforschungsbereich 880" (SFB 880) identified a combination of propeller slipstream with a blown flaps system as a promising approach. The declared goal is to make existing small airfields and infrastructure in urban areas available for airlines by adequate designs for efficient civil transport type STOL aircraft. [2] New aircraft of this segment would be equipped with advanced technologies for drastic airframe and engine noise reduction. They would represent a community-friendly aircraft designed for operations much closer to the home of passengers than possible today, operating effectively in point-to-point services between metropolitan areas. The overall working hypothesis of the SFB 880 states that active high lift systems with high levels of aerodynamic efficiency add significant value to future civil transport. These active systems can provide higher flexibility in the generation of high lift for aircraft families and aircraft upgrades, allow significant reductions of airframe noise emissions, and finally provide a technically feasible and economically viable path towards short takeoff and landing capabilities. Therefore, the SFB 880 gathers all relevant research fields to efficient clusters. In other contributions to this conference overviews of the "aerodynamics", "aeroacoustics" and "flight dynamics" clusters will be presented as well [3-5].

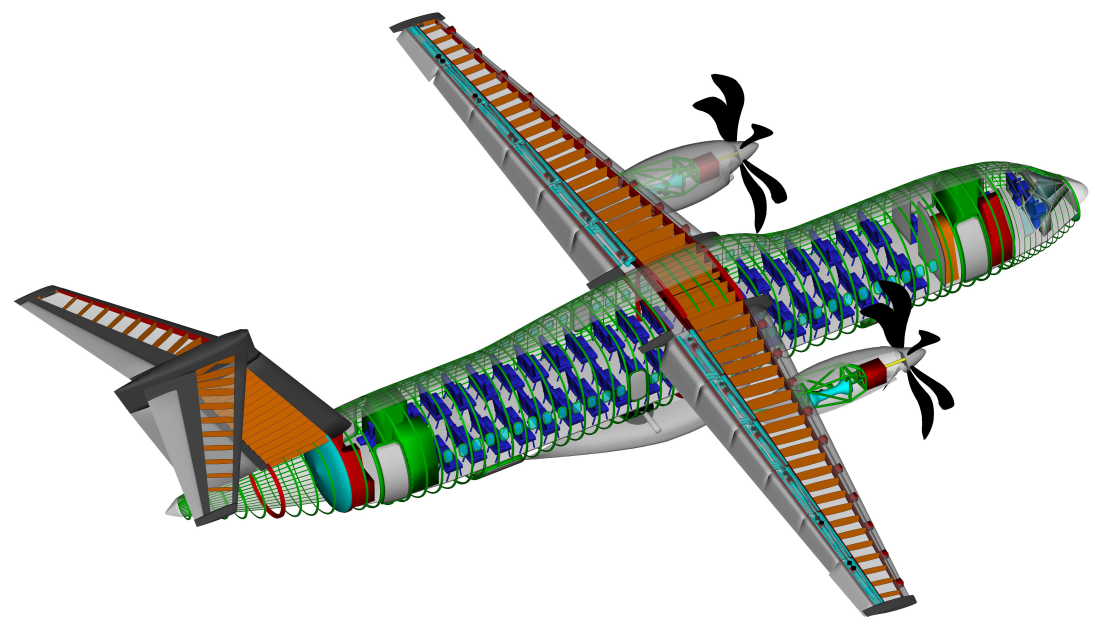

Fig. 1 SFB 880 aircraft design, 100 passengers, range 2000 km, $M=0.74$, in landing configuration

A configuration for a turbo-propeller powered aircraft equipped with a micro-compressor blown flap system has been designed combining circulation control with deflected propeller slipstream effects, depicted in Figure 1 with the basic aircraft data given in Table 1

Such a technology combination was investigated before in prototype flight test programs by NASA for the Lockheed NC-130B "Hercules" [6] and the Shin-Meiwa UF-XS [7] in the 1960s. The flight tests confirmed remarkable low 
airspeed flight performances, but with large energy investments realized by additional jet engines and thus weight penalties. In the SFB 880, a modern cruise optimized civil transport type aircraft has been developed incorporating comprehensive most recent knowledge about high efficient circulation control technology [8]-10]. A systems architecture based on along the wingspan distributed micro-compressors for pressurized air prevents excessive weight penalties and keeps the engine sizes on a reasonable level. The specific design of the micro-compressors is part of the research within the SFB 880 to achieve the ambitious goals of the project [11].

Table 1 SFB-Aircraft basic data

\begin{tabular}{lcc}
\hline Wing area & $95 \mathrm{~m}^{2}$ & $1022.6 \mathrm{ft}^{2}$ \\
Horizontal tail area & $27 \mathrm{~m}^{2}$ & $290.6 \mathrm{ft}^{2}$ \\
Vertical tail area & $27 \mathrm{~m}^{2}$ & $290.6 \mathrm{ft}^{2}$ \\
Wing span & $28.78 \mathrm{~m}$ & $94.4 \mathrm{ft}^{2}$ \\
MAC & $3.428 \mathrm{~m}$ & $11.2 \mathrm{ft}$ \\
Aspect ratio & 9 & \\
Sweep angle & $10^{\circ}$ & \\
Dihedral angle & $-2^{\circ}$ & \\
MTOW & $41.43 \mathrm{t}$ & $91,339 \mathrm{lbs}$ \\
Engines & $2 \times 8000 \mathrm{~kW}$ & $2 \times 10,728 \mathrm{SHP}$ \\
Static Thrust & $2 \times 94.3 \mathrm{kN}$ & \\
\hline
\end{tabular}

Although the above mentioned prototype programs show that a combination of these active high-lift technologies is promising [12], they also reveal flight mechanical drawbacks. Especially in the lateral motion such aircraft show a dissatisfying or even critical behavior leading to unfavorable handling qualities, control deficiencies and instabilities [6]. Hefferley et al. [13] stated that common "powered-lift" aircraft problems are

- Poor turn coordination

- Relatively rapid spiral divergence

- Low roll damping

- Low frequency and damping of the dutch roll mode.

Obviously, the directional stability appears to be a critical aspect. In the past the described problems were mainly attributed to the reduced authority of control surfaces and stabilizer at low airspeeds due to the low dynamic pressure at low airspeeds. However, although this is certainly one of the problems, the flight tests with the various "'powered-lift"' prototypes showed different flight characteristics being rather unique for each prototype. This leads to the conclusion that the reasons for this behavior might be more complex than expected, asking for further comprehensive flight mechanical investigations based on latest aerodynamic flow solver results.

In a close cooperation with the SFB 880 project partners from aerodynamics research it is possible to design comprehensive flight mechanical models for full aircraft flight dynamics simulation. Based on results of DLR's most advanced flow solvers [14] the models are developed to analyze and confirm the desired flight characteristics. These results are the key to identify the cause for drawbacks in terms of stability, controllability and handling qualities for the SFB aircraft. The focus of this paper lies on the presentation of the capabilities of this aircraft, but also on the potential 
causes for dissatisfactory aircraft behavior and the specific flight dynamic characteristics of the investigated aircraft configuration.

\section{Longitudinal Motion}

For the desired exceptional high-lift performance the SFB 880 aircraft relies on the combination of propeller slipstream effects and a blown flaps system along the wingspan. This active high-lift system generates large parts of the high lift coefficient values by the blown flaps. The integrated system depicted in Fig. 2 is based on a single hinged plain flaps with a Coandă-surface at its knee. The characterizing figure describing the performance setting of the system is

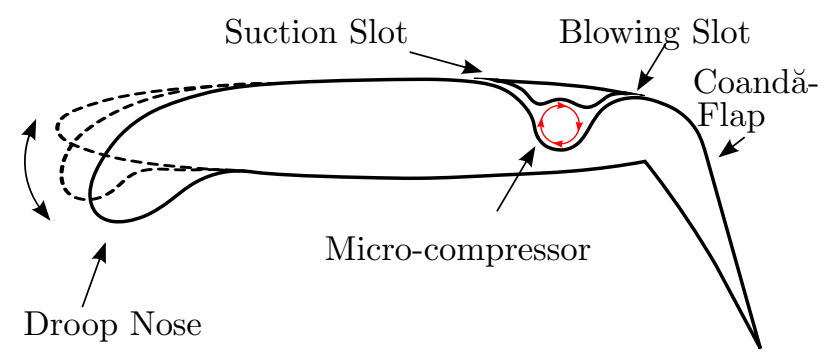

Fig. 2 Schematic diagram of the SFB 880 wing profile and the active high-lift system integration

the dimensionless jet momentum coefficient $C_{\mu}$. It relates the air mass flow $\dot{m}_{j e t}$ and velocity $v_{j e t}$ of the blown flaps system's jet flow to the surrounding dynamic pressure $q_{\infty}$ and the aircraft's wing area $S$ by

$$
C_{\mu}=\frac{\dot{m}_{j e t} \cdot v_{j e t}}{q_{\infty} \cdot S}
$$

The additional lift due to the integrated blown flap system can be divided in two major areas. In Figure 3 the schematic behavior is shown. Normally, for a strong flap deflection the flow cannot follow the flap surface (a). A blowing
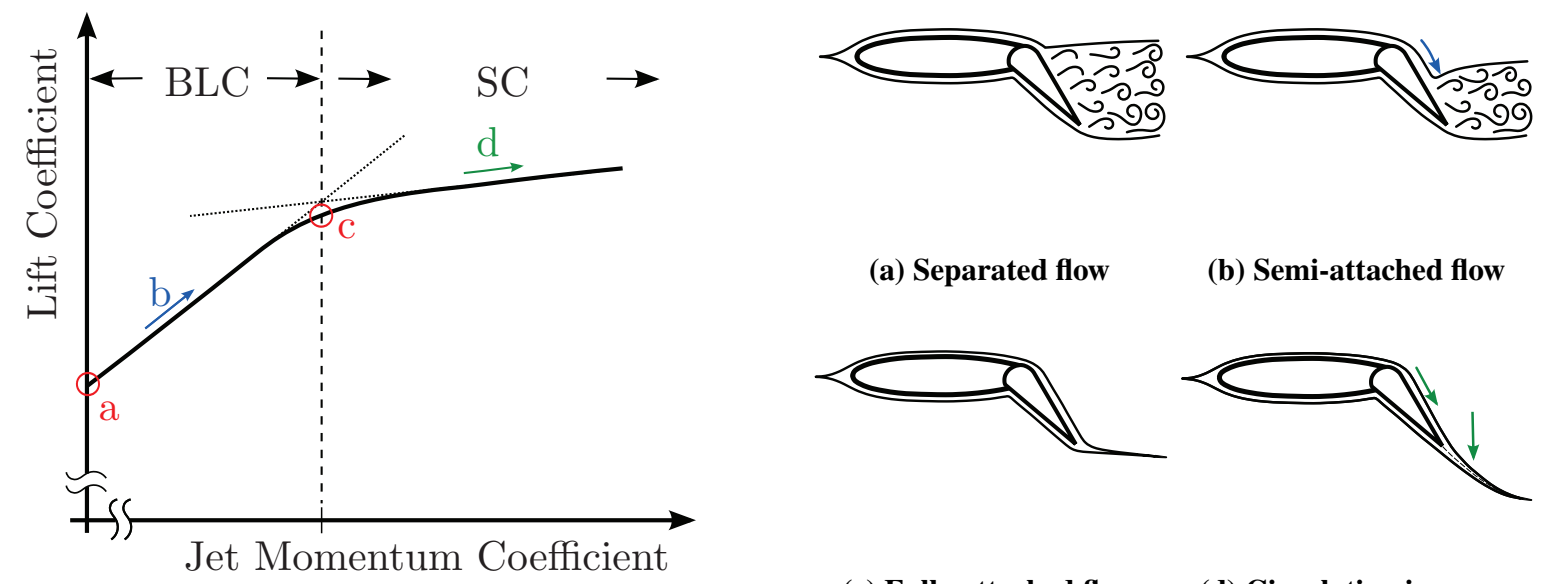

(a) Separated flow

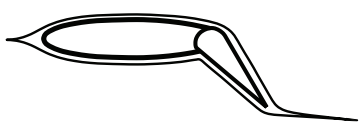

(c) Fully attached flow (b) Semi-attached flow

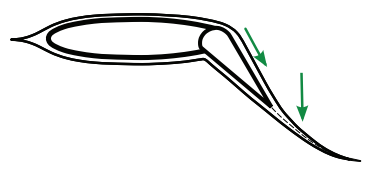

(d) Circulation increase

Fig. 3 Flow transition for blown flaps 
increase leads to an incremental reattachment to the flap surface (b). In the following this area will be mentioned as the boundary-layer control (BLC) area. Once enough blowing momentum is achieved the flow is fully reattached (c). A further blowing momentum increase leads to a circulation increase (d) and will be mentioned as super-circulation (SC). Nevertheless, the super-circulation is still a special type of boundary layer control. Obviously, the gradient of the SC is not as steep as the BLC gradient. Thus, the efficiency in lift generation is higher in the BLC area. The fully attached flow appears to be an optimum and therefore the related jet momentum will be considered as the reference value.

For a detailed understanding of the effects causing the favorable and unfavorable characteristics it is necessary to transfer high-fidelity CFD data [15] and aerodynamic knowledge about the governing effects to capable flight mechanics models for fast time simulations [16]. For the longitudinal motion the relevant forces and moments of the wing/fuselage (WF) already indicate the high performance potential of the high lift system, depicted in Figure 4 w.r.t the angle of attack (AoA) for a flap deflection of $\delta_{F l}=65^{\circ}$. A proper model of the aerodynamics needs
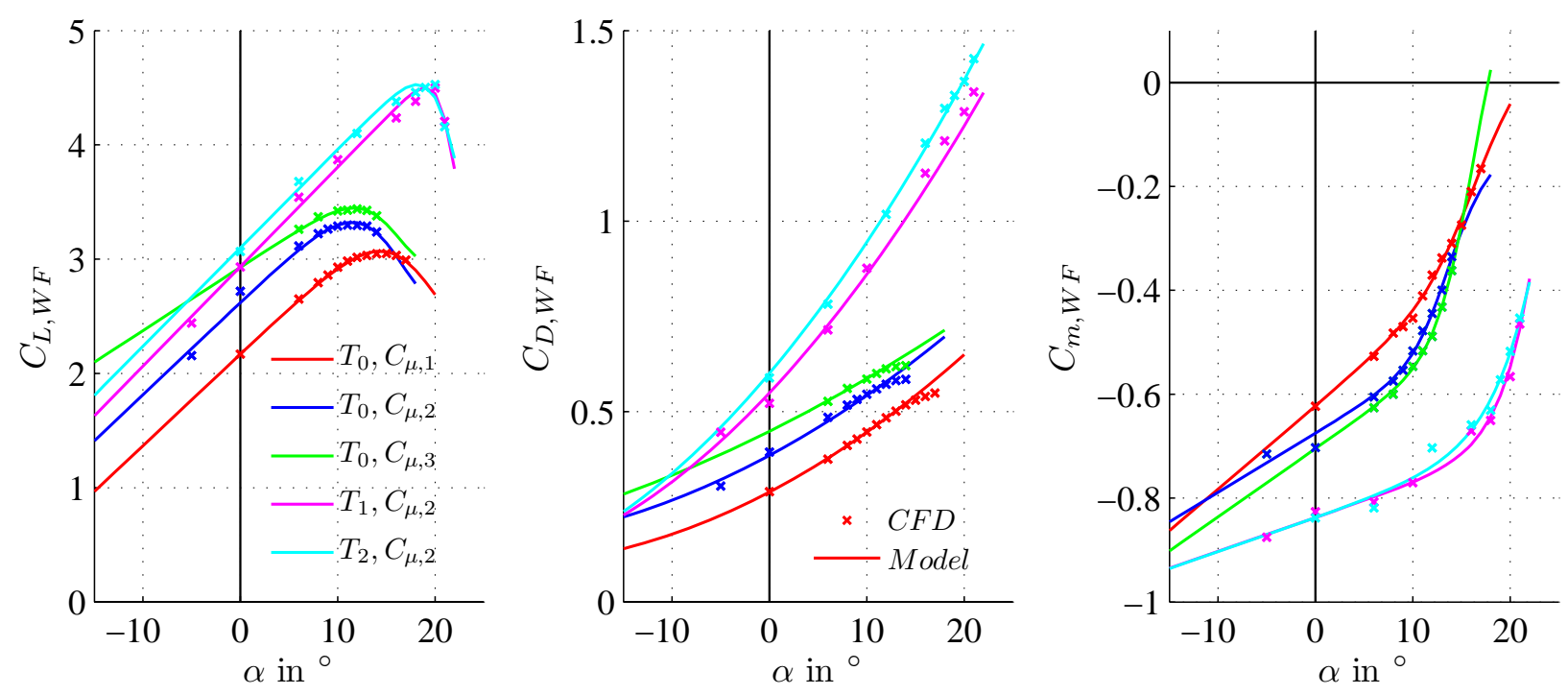

Fig. 4 Lift, drag and pitching moment model results (lines) and CFD-Data (crosses) for the longitudinal motion dependent on jet momentum $\left(C_{\mu}\right)$ and engine thrust $(T)$

to incorporate influences from both the blowing system and the propeller slipstream separately, as the propeller slipstream also adds large lift contributions. These influences are reflected by different jet momentum settings $\left(C_{\mu, 1}=0.02, C_{\mu, 2}=C_{\mu, R e f}=0.033, C_{\mu, 3}=0.045\right)$ of the blowing system with and without propeller slipstream effects reflected by the different thrust settings $\left(T_{0}=0, T_{1}=40.9, T_{2}=49.4 \mathrm{in} \mathrm{kN}\right.$ per engine). Along with the desired lift increase, strong effects on drag and pitching moment appear. The lift performance without propeller slipstream is already above $C_{L}>3$, but achieved at low angles of attack. In the following, the angles of attack of the maximum lift will be mentioned as maximum AoA. Both, lift and maximum AoA are shifted to higher values by the propeller slipstream. However, the drag also increases significantly. The presented thrust values are equivalent to medium 
performance settings of the installed engines close to the ground at low airspeed. Available extra data points (not depicted) indicate that the lift, pitching moment and maximum AoA are already close to their saturation, whereas the drag increases almost linearly with further thrust increases. Therefore, the lift and pitching moment models are limited to thrust values of $T_{2}$, while the drag increase is linearly extrapolated for higher thrust settings.

The underlying model equations for the longitudinal motion are based on a modular approach for each influencing effect assuming superposition principles. Lift and pitching moment are designed as a two-point model, separating the aerodynamics of the horizontal tail-plane (HTP) from the WF.

$$
\begin{gathered}
C_{L}=C_{L, W F}(\alpha)+C_{L, F l}\left(C_{\mu}, \alpha, T\right)+C_{L, \text { Stall }}\left(C_{\mu}, \text { alpha }, T\right)+\frac{S_{H T P}}{S} \cdot C_{L, H T P}\left(\alpha_{H T P}, C_{\mu}\right) \\
C_{m}\left(\alpha, C_{\mu}\right)=C_{m, W F}(\alpha)+C_{m, F l}\left(C_{\mu}, \alpha, T\right)+C_{m, \text { Stall }}\left(C_{\mu}, \text { alpha }, T\right)-\underbrace{\frac{S_{H T P}}{S} \cdot \frac{l_{X}}{l_{\mu}} \cdot C_{L, H T P}}_{C_{m, H T P}}
\end{gathered}
$$

The aerodynamics of WF and HTP are linked by a wing downwash model describing the additional downwash angle $\varepsilon$ at the HTP

$$
\varepsilon\left(C_{L, W F}, C_{\mu}\right)=\varepsilon_{C_{L, W F}=0}+\varepsilon_{C_{\mu}}+\left(\frac{\partial \varepsilon}{\partial C_{L, W F}}+\varepsilon_{C_{\mu} C_{L}}\right) \cdot C_{L, W F}
$$

which also considers specific jet momentum influences. This way the lift of the HTP can be calculated by

$$
C_{L, H T P}=C_{L \alpha, H T P} \cdot f_{P G} \cdot \underbrace{\left(\alpha+\varepsilon\left(C_{L, W F}(t-\tau), C_{\mu}\right)+i_{H T P}+\alpha_{d y n}\right)}_{\alpha_{H T P}\left(C_{L, W F}, C_{\mu}\right)}+C_{L, \eta} \cdot \eta
$$

All AoA related coefficients are airspeed corrected by a Prandtl-Glauert-Factor

$$
f_{P G}=\frac{\sqrt{1-M_{C F D}^{2}}}{\sqrt{1-M^{2}}}
$$

considering aerodynamic variation with increasing airspeed away from the CFD design airspeed at $M_{C F D}=0.15$. The stall behavior is modeled by

$$
\begin{gathered}
C_{L, \text { Stall }}=f \cdot\left(1+\tanh \left(a_{1} \cdot\left(\alpha-\alpha^{\star}\right)\right)\right) \\
f\left(C_{\mu}, T\right)=f_{\text {Ref }}+\tilde{f}\left(C_{\mu}\right)+\tilde{f}(T) \\
a_{1}\left(C_{\mu}, T\right)=a_{1 R e f}+\tilde{a}_{1}\left(C_{\mu}\right)+\tilde{a}_{1}(T) \\
\alpha^{\star}\left(C_{\mu}, T\right)=\alpha_{R e f}^{\star}+\tilde{\alpha}^{\star}\left(C_{\mu}\right)+\tilde{\alpha}^{\star}(T)
\end{gathered}
$$




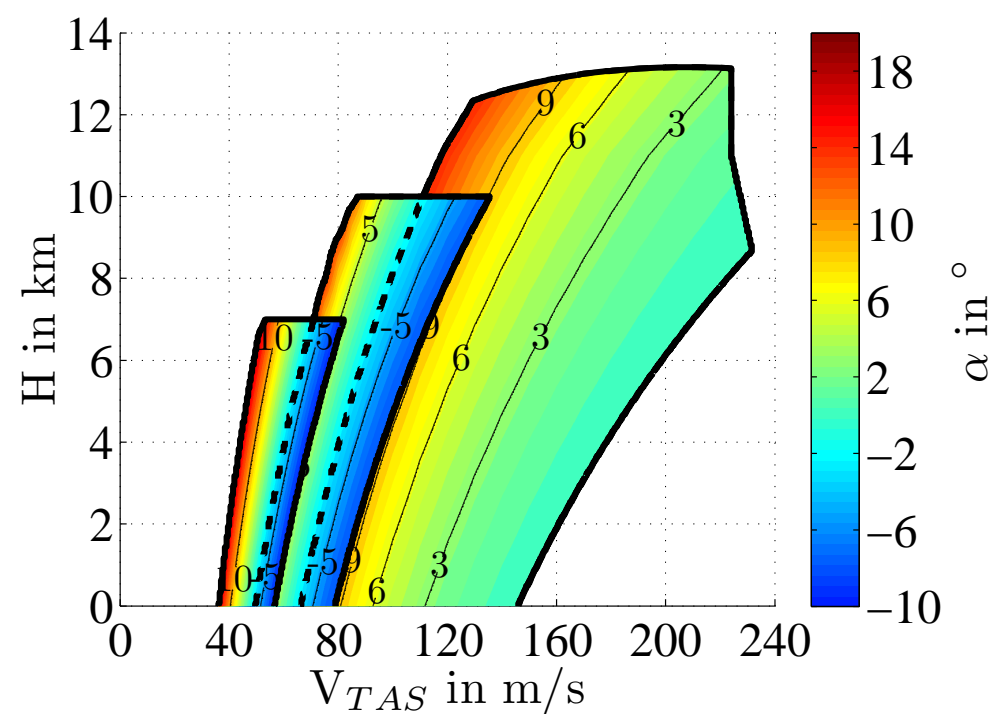

Fig. 5 Envelopes of the SFB-Aircraft

depending on the jet momentum and thrust setting. The factors $f, a_{1}$ and $\alpha^{\star}$ describe the range, the abruptness and the onset point of the stall. The influences of blown flaps and thrust are integrated as restricted look-up tables indicated by $\sim$ with linear interpolation between the known states. The basis for the stall model is the aerodynamic behavior at the reference point at $T_{0}$ and $C_{\mu, 2}=C_{\mu, R e f}$. The stall characteristics of the pitching moment are modeled similarly. The drag is modeled with a quadratic lift dependent approach describing the parasite $\left(C_{D 0}\right)$ and the induced drag components $\left(C_{D i}\right)$

$$
C_{D}=\underbrace{C_{D 0, W F}+C_{D 0, H T P}}_{C_{D 0}}+\underbrace{k_{1} \cdot C_{L}+k_{2} \cdot C_{L}^{2}}_{C_{D i}}+C_{D, F l}\left(C_{\mu}, T\right)
$$

including slight correctional terms for jet momentum and thrust. Further details of the underlying longitudinal aerodynamic model can be found in [16, 17].

\section{Flight Performance}

The flight performance of the current design is remarkable for a transport type aircraft of this size. Though, in an early design phase the first wing profile with a plain nose created some drawbacks [16]. Since the usable airspeed range was impractical and the gap between full-flap and cruise envelope was large, a redesign incorporated a droop-nose wing profile realized by a flexible morphing wing architecture [18] which resulted in a wider usable airspeed range. Additionally, an intermediate flap setting was introduced assuring sufficient overlapping of both envelopes to guarantee safe transitions. Figure 5 shows the envelopes of the current design. The AoA indicated by the color coding is pointing out, that still large differences in AoA appear in the intersection areas between the different flap settings. However, these angles can be influenced by variation of the performance of the BLC-system. Furthermore, the envelopes show a 
promising potential to achieve remarkable slow-flight capabilities and economically reasonable cruise performances for a commercial transport type aircraft.

The potential of the aircraft to change the AoA or the pitch attitude due to a variation of the blowing performance at a selected flight path angle is extraordinary. Similar capabilities to uncouple flight path and pitch attitude respectively AoA are known from NASA's Quiet Short-Haul Research Aircraft (QSRA) [19] or the Japanese prototype "ASKA", which were investigated in the eighties and early nineties [20]. As an example, the ASKA had a flight path angle control system giving the pilot the opportunity to select a flight path angle by an additional lever. The upper surface blowing configuration used a control system based on the throttle and spoiler to command the necessary L/D-ratio to achieve the desired flight path angle.

The SFB-aircraft has even more capability to achieve a desired flight path at a desired AoA or pitch attitude. Figure6 shows trimmed states for variations of flight path, power setting and jet momentum coefficient. It implies that the aircraft can increase or decrease its attitude at a given engine power setting simply by changing the jet momentum of the BLC-system with almost any change in flight path angle. An adequate control system could vary the input parameters such, that the aircraft operates at a constant pitch attitude or AoA. It is even thinkable to support the rotation of the aircraft during flare maneuver close to the ground. This is an important aspect, as a rotation will be necessary for most approach cases due to the fact that the aircraft already operates at negative pitch attitudes for standard approach flight path angles of $\gamma=3^{\circ}$ at airspeeds above $V>46.5 \mathrm{~m} / \mathrm{s}$. 


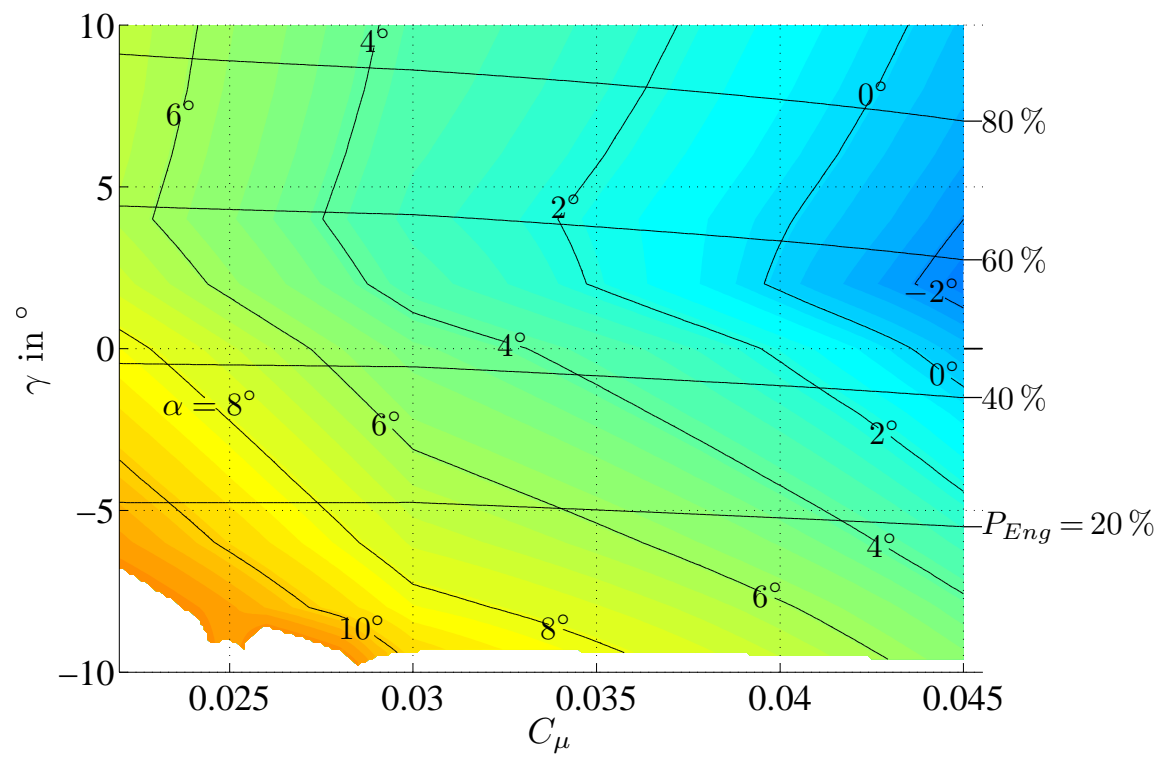

(a) Angle of attack $\alpha$

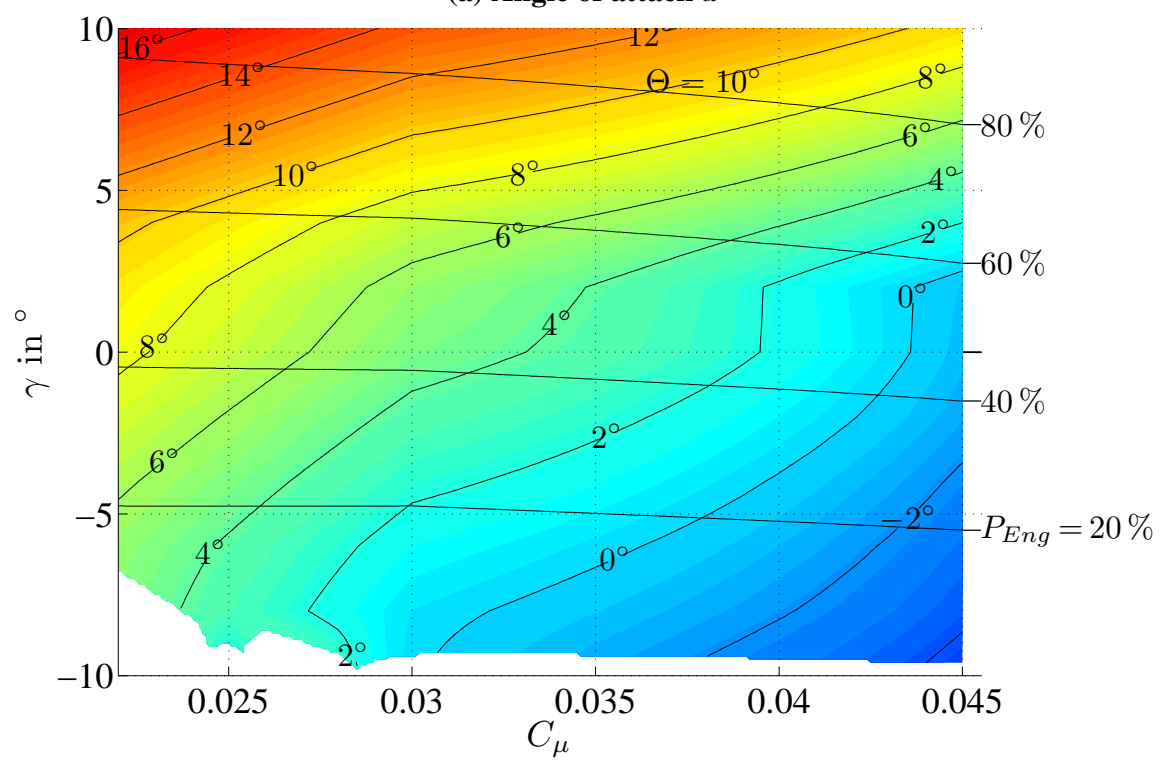

(b) Pitch attitude $\Theta$

Fig. 6 Flight path angle ranges at an approach airspeed of $V_{A p p}=45 \mathbf{m} / \mathbf{s}$ 
The climb/descent performance of this aircraft is depicted in Figure 7 It underlines the potential for slow or steep approaches, but reveals a weakness of such high-lift system technologies. The steep landing approach capability fulfills the desired design targets for this aircraft, as well as the achievable low approach airspeeds do. However, the climb rates with one engine inoperative (OEI) are critical. This is indicated by the dashed line representing a flight path angle equivalent to a vertical speed of $2.1 \% \cdot V_{T A S}$. This is the required climb performance with the critical engine failing according to EASA's Certification Specification 25 (CS-25 [21]). This design includes counterrotation propellers so that both engines have the same criticality in case of failure. A comparison with a blown-flap-only configuration shows, that this shortcoming can be attributed to the propeller slipstream-flap impingement [10]. The main reasons for the OEI climb performance are the significantly reduced maximum AoA at the failing engines wing half and the enormous drag increase with high thrust values, while the lift coefficient is already saturated. A jet engine would have better characteristics for go-around with OEI, as Figure 7c shows. However, without the slipstream the aircraft would show a significantly reduced low airspeed performance.

A better climb performance in case of OEI can only be achieved by a reduced flap setting with better L/Dcharacteristics. Previous STOL-aircraft were facing similar challenges and provide solutions in terms of quick flap reconfiguration. The already mentioned "ASKA" had difficulties to achieve enough climb rate in full flap configuration [22]. A go-around switch was installed at the primary control lever (flight path control), which allows the pilot to initiate a flap retraction and the execution of the maneuver simultaneously with the same hand. 


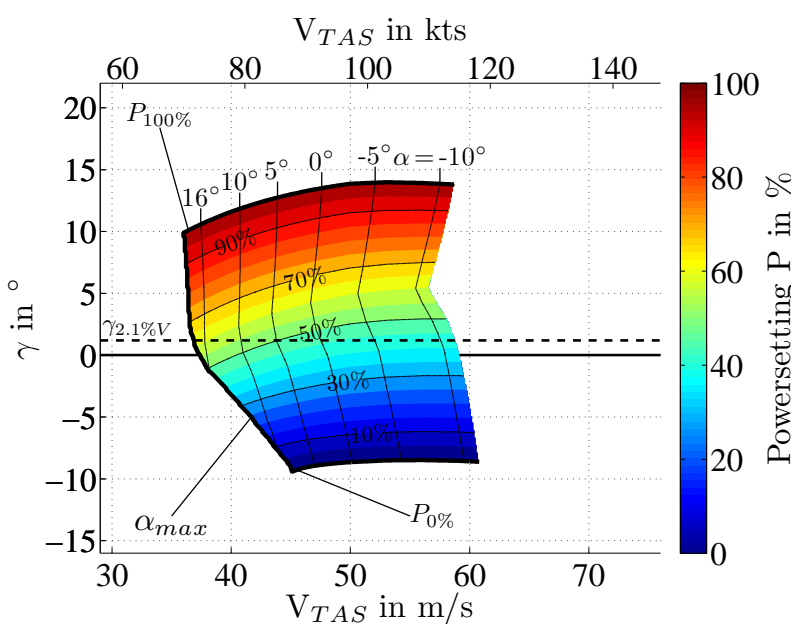

(a) All engines operative

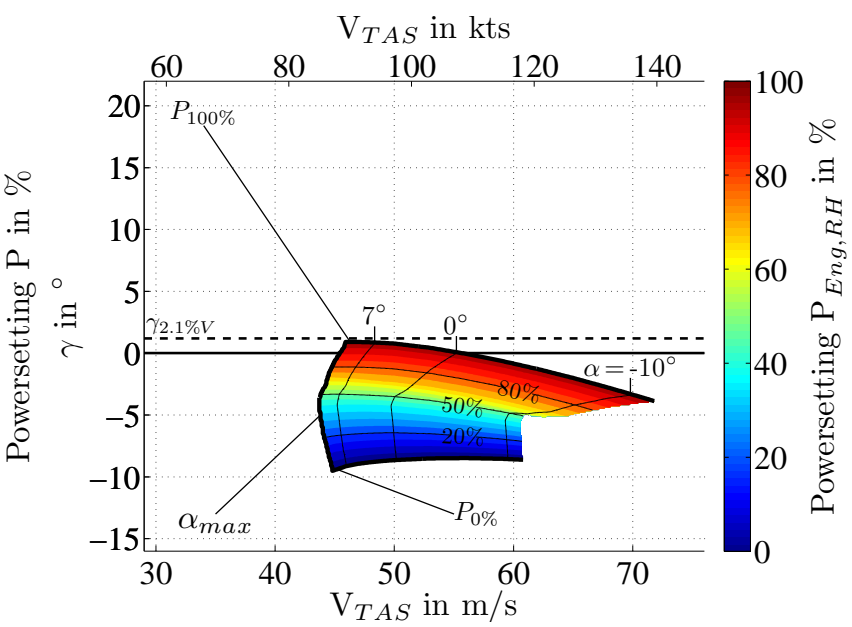

(b) One engine inoperative

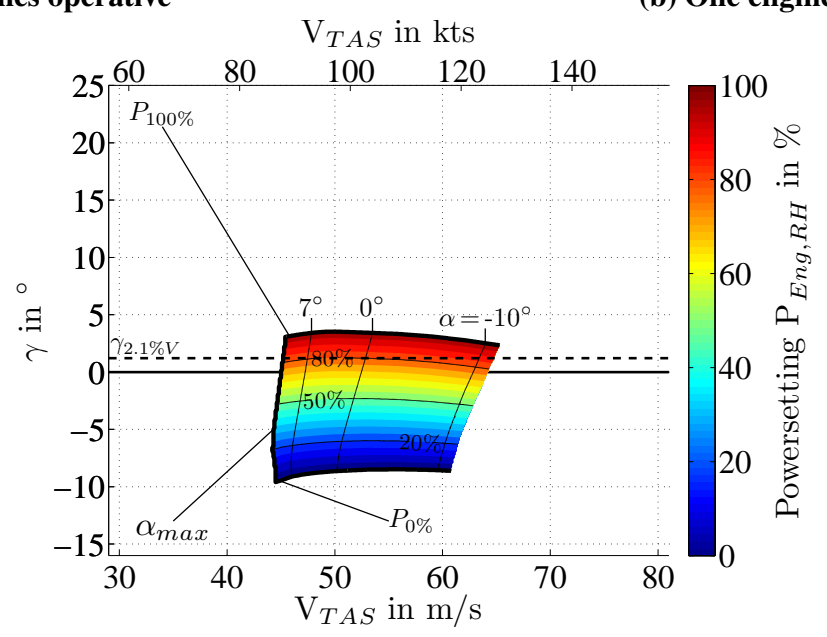

(c) One engine inoperative, jet engine assumed

Fig. 7 Climb/Descent performance of the SFB 880 aircraft

\section{Lateral Motion}

The numerous studies attesting poor lateral-directional handling qualities of STOl-aircraft draw the attention to the lateral motion and its aerodynamics. Besides the expected decrease of stability and control due to low dynamic pressures, aerodynamic CFD results showed highly non-linear behavior. Consequently, the aircraft motion in sideslip has been investigated thoroughly. An aircraft component wise flight mechanics model approach has been developed in order to quantify the various influences of each component during maneuver flight. The models were derived from high-fidelity CFD data sets, which offered the chance to attribute forces and moments to each of the aircraft components in terms of wing, fuselage, vertical or horizontal tail. Therefore, the forces and moments are modeled by an universal function

$$
C_{X, C o m p}(\beta)=\tilde{C}_{X \beta} \cdot \beta+\tilde{F}_{X} \cdot\left(\tanh \left(\tilde{K}_{X} \cdot\left(\beta-\Delta \tilde{\beta}_{X}\right)\right)+\tanh \left(\tilde{K}_{X} \cdot\left(\beta+\Delta \tilde{\beta}_{X}\right)\right)\right)
$$


where $\mathrm{X}$ indicates each of all three forces and three moments. $\tilde{C}_{X \beta}$ describes the linear behavior, whereas $\tilde{F}_{X}, \tilde{K}_{X}$ and $\Delta \tilde{\beta}_{X}$ are adjustment factors for the hyperbolic tangent which can be fitted to the nonlinear character of the underlying CFD data set. These factors are introduced as thrust and AoA depended look-up tables indicated by . Within these look-up tables linear interpolation allows an approximation and transition between different thrust and AoA states. Outside of the approved boundaries the factors are fix without any extrapolation.

The influence of the propeller slipstream is reflected by different thrust settings $\left(T_{0}=0, T_{1}=40.9, T_{3}=57.0 \mathrm{in} \mathrm{kN}\right.$ per engine) and in addition for two angles of attack $\left(\alpha=0^{\circ} \& \alpha=10^{\circ}\right)$ at a constant reference jet momentum. The component portions of the yawing moment are presented in Figure 8 A dependence of the lateral motion on AoA and thrust has been determined before for other aircraft configurations as for example the QSRA [23]. Both, SFB-aircraft and QSRA, have in common that they are highly thrust-to-lift coupled. However, the SFB-aircraft still shows significant differences.

Typically, a positive linear gradient for the yawing moment along sideslip angle indicate directional stability, as it appears here for zero-thrust at the vertical tailplane (VTP). The fuselage usually has a destabilizing effect, which is interfered by the VTP. Obviously, in this case the destabilizing fuselage influence becomes an important factor. It is remarkable that even the VTP itself partly fails to provide a stabilizing effect. Furthermore, the stabilizing and destabilizing effects seem to switch for certain thrust/AoA combinations. The graphs in Figure 9 show the yawing moment in total. The major effect leading to this behavior is the interaction of the strongly deflected propeller slipstream with the aft of the aircraft's body. The propeller slipstream attaches to the fuselage creating suction peaks, which lead to additional forces and moments. Furthermore, for some combinations of AoA and thrust the vertical tail becomes destabilizing, since the flow wraps around the fuselage and the flow direction at the VTP location turns locally opposite to the global sideslip angle. These extraordinary aerodynamic effects were investigated and explained in detail by the aerodynamic partner projects within the SFB 880 [15]. The presented model approach is capable to describe this effect as a function of AoA and thrust. Figure 10 shows the flow around the aircraft during sideslip, showing that the sideslip interferes with the aft fuselage.

Usually, the longitudinal motion is not affected considerably by sideslip. In this case the interaction of slipstream and fuselage has a strong impact especially in terms of pitching moment. Therefore, the universal function (12) has been extended for longitudinal modeling, which shows axial symmetric behavior with respect to sideslip angle, unlike the point symmetric characteristics of the lateral motion. Instead of using absolute input values for sideslip for the forces and moment of the longitudinal motion, the extension

$$
C_{X, l o n, \operatorname{Comp}}(\beta)=-\tanh \left(K_{m} \cdot \beta\right) \cdot C_{X, \operatorname{Comp}}(\beta)
$$

has been applied to the universal function in order to keep the function continuously differentiable. The factor $K_{m}$ is 


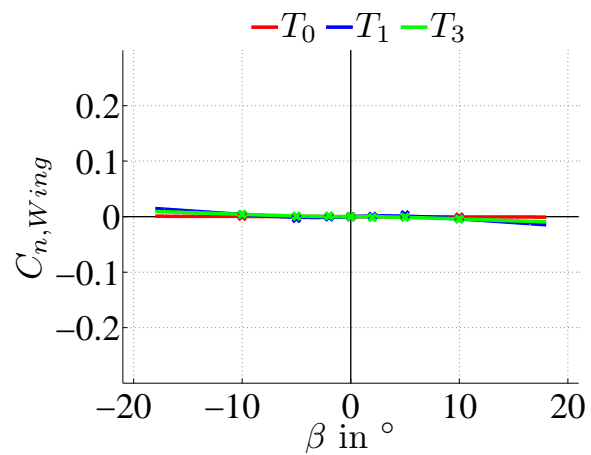

(a) Wing $\alpha=0^{\circ}$

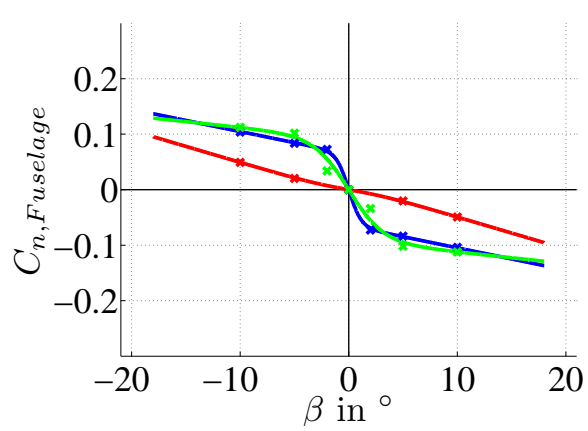

(c) Fuselage $\alpha=0^{\circ}$

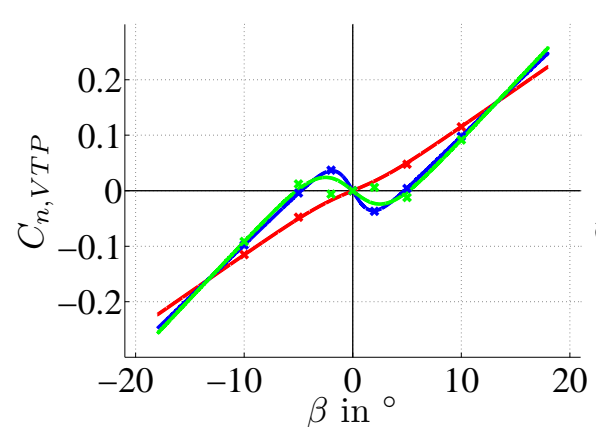

(e) Vertical tail $\alpha=0^{\circ}$

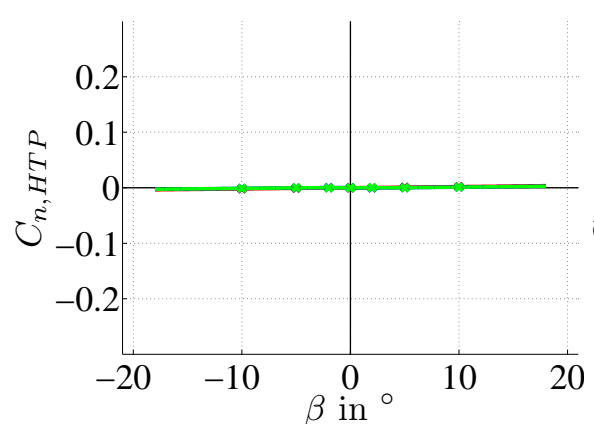

(g) Horizontal tail $\alpha=0^{\circ}$

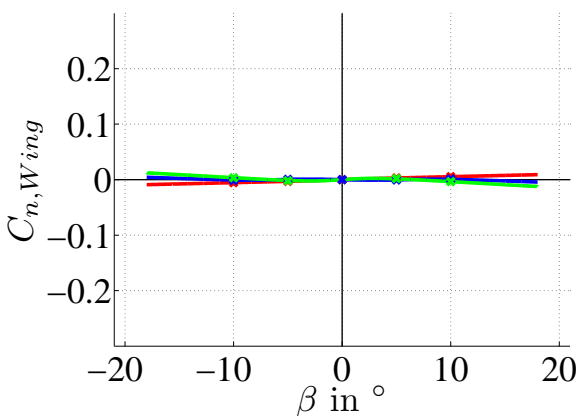

(b) Wing $\alpha=6^{\circ}$

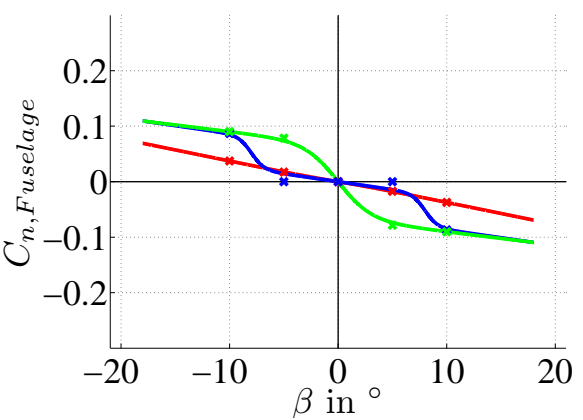

(d) Fuselage $\alpha=6^{\circ}$

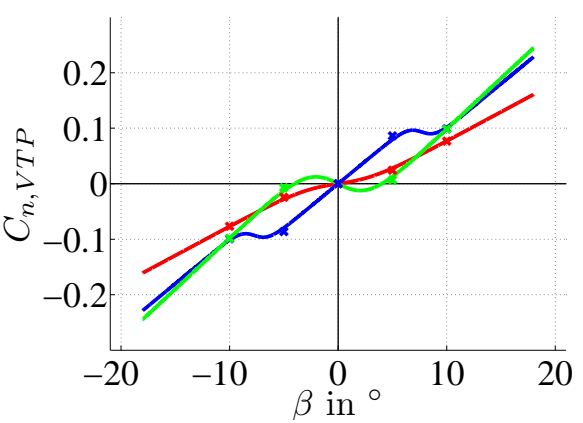

(f) Vertical tail $\alpha=6^{\circ}$

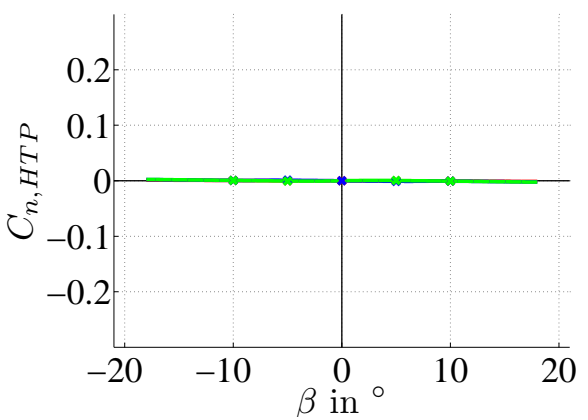

(h) Horizontal tail $\alpha=6^{\circ}$

Fig. 8 Yawing moment component portions, CFD data(crosses) \& model (lines) 


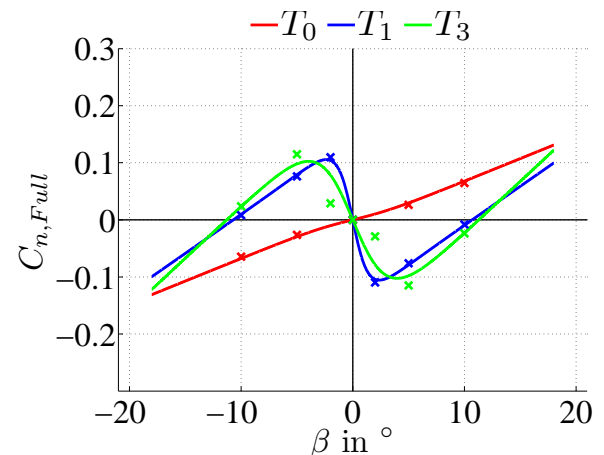

(a) At angle of attack $\alpha=0^{\circ}$

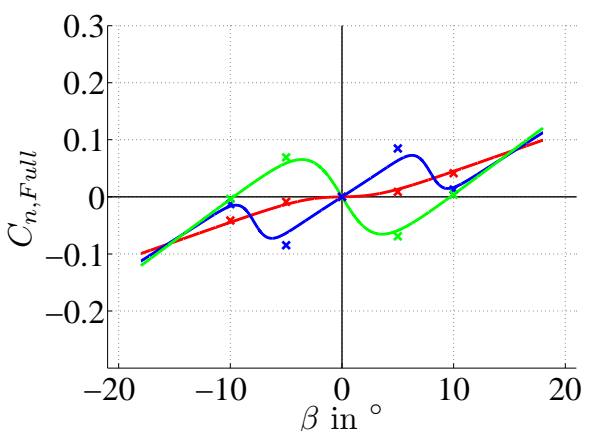

(b) At angle of attack $\alpha=6^{\circ}$

Fig. 9 Yawing moment due to sideslip

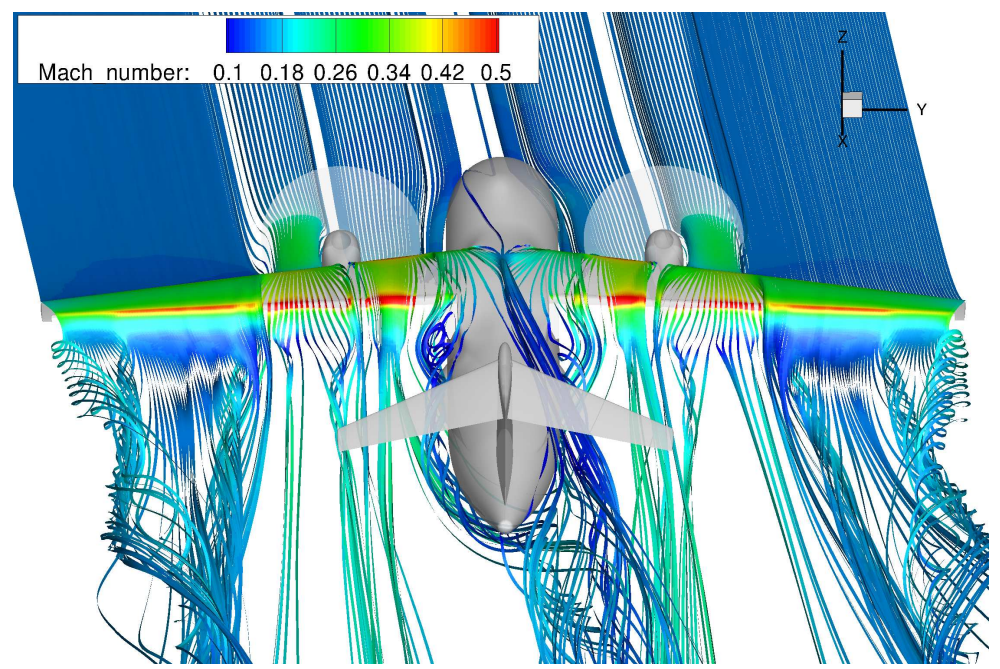

Fig. 10 Flow around the aircraft at a sideslip of $\beta=5^{\circ}$ at $T_{3}$ and $\alpha=0^{\circ}$ from Keller et al. [10]

chosen such, that the function shows no abrupt change of sign when passing $\beta=0^{\circ}$, but a continuous and smooth behavior. The graphs in Figure 11 show the sum of all component portions for the pitching moment. Strong up-pitching moments occur in most cases. Similar to the impressions of the yawing moment, certain Thrust/AoA combinations induce strong changes in the direction of the pitching moment.

The presented moments (yaw and pitch) are the most affected by the propeller slipstream. The remaining forces and moments are affected as well. However, the influence is of smaller dimension, and thus not depicted here. The rolling moment shows an indifferent small scaled behavior along sideslip angle. The sideforce is the most influenced force, which is already reflected by the yawing moment. The lift decreases almost linearly in a range around $\Delta C_{L}\left(\alpha=0^{\circ}, \beta= \pm 10^{\circ}\right)=-0.25$ for a sideslip angle in a range of $\beta= \pm 10^{\circ}$ at zero AoA. Higher angles of attack reduce the lift loss to $\Delta C_{L}\left(\alpha=6^{\circ}, \beta= \pm 10^{\circ}\right)=-0.15$. The drag is varies in ranges of $\Delta C_{D}= \pm 5 \cdot 10^{-2}$ for sideslip angle variations under slipstream influence. 


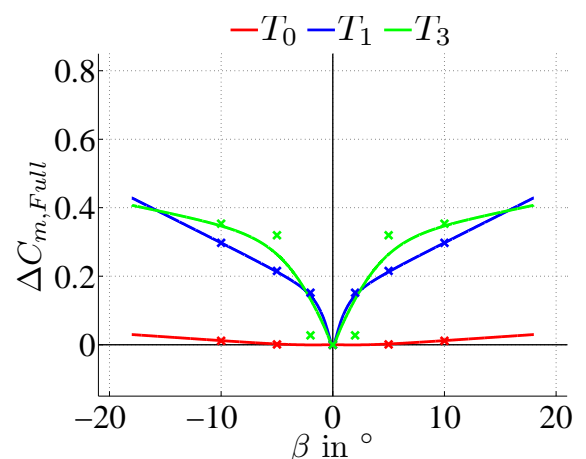

(a) At angle of attack $\alpha=0^{\circ}$

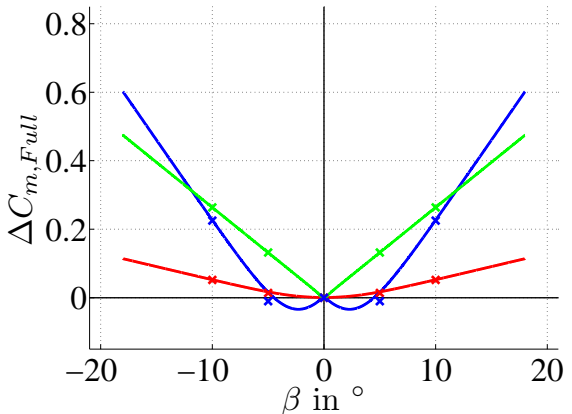

(b) At angle of attack $\alpha=6^{\circ}$

Fig. 11 Pitching moment due to sideslip

This model is integrated into the full aircraft flight dynamics model as an increment to the basic full motion aerodynamic model. The complete simulation model also incorporates various additional dynamics for example for the engine dynamics or the actuator dynamics of the control surfaces [17].

\section{Flight Dynamics}

In order to quantify the resulting flight dynamics and handling qualities criteria are often defined for linearized models. For evaluation of the aircraft's eigenmotions the Military Handbook 1797A offers a set of damping and eigenfrequency criteria [24]. In addition various activities of NASA, FAA and AGARD to develop STOL aircraft criteria can be considered as well [13, 25]. For this investigation the model has been trimmed and linearized at different operating points. The first parameter study consists of a variation of airspeed in the relevant range for full-flap setting at an altitude of $A l t=300 \mathrm{~m} \equiv 984 \mathrm{ft}$. The target is to identify the influence due to the respective changes in AoA and thrust on the eigenmotions. The speed and altitude correspond to a typical situation in final approach phase close to the final approach fix.

The locations of the linearized system's roots in the complex plane of Figure 12 show the movement with the airspeed. The boundaries for the longitudinal motion in terms of phugoid $(\mathrm{PH})$ and short period motion $(\mathrm{SP})$ are derived from MIL-HDBK-1797A. For the lateral eigenmotions, in addition to the MIL-HDBK, a STOL aircraft specific criterion is introduced for the spiral motion (S), which is equivalent to a time-to-double of more than $t_{2 S, S T O L}=20 \mathrm{~s}$ [26]. The boundaries for the dutch roll (DR) are depicted as well. These constraints are fulfilled if the systems roots are on the left side of the corresponding boundary. For the rolling motion no further boundaries were applied. Obviously, the airspeed variation has no significant effect on the longitudinal motion in Figure 12a, showing the the low frequent, low damped phugoid motion and the high frequent, well damped oscillation of the short period, which typically is slightly airspeed dependent. However, the system shows strong reactions in the lateral motion, depicted in Figure $12 \mathrm{~b}$ The damping of the oscillating dutch roll increases significantly with higher airspeed. The largest root movements and interactions can 


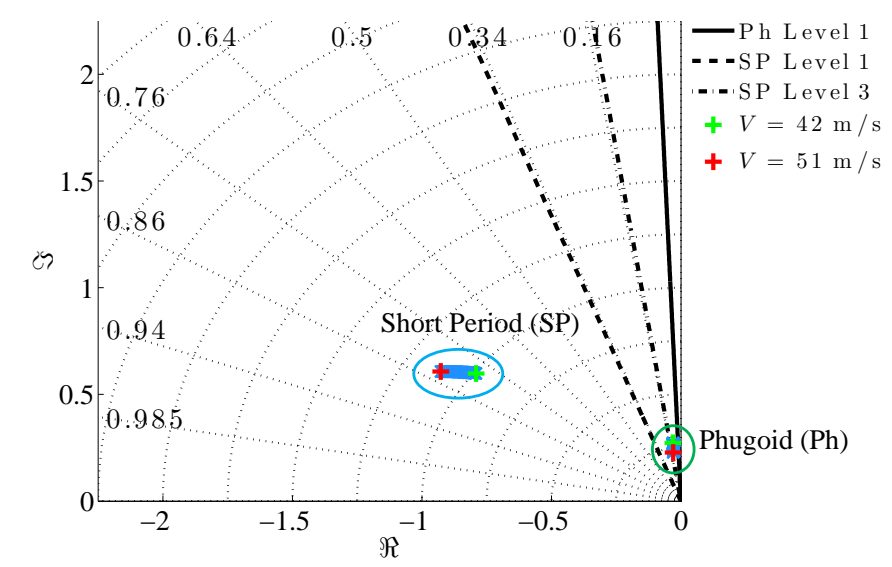

(a) Longitudinal Motion $\beta=0^{\circ}$

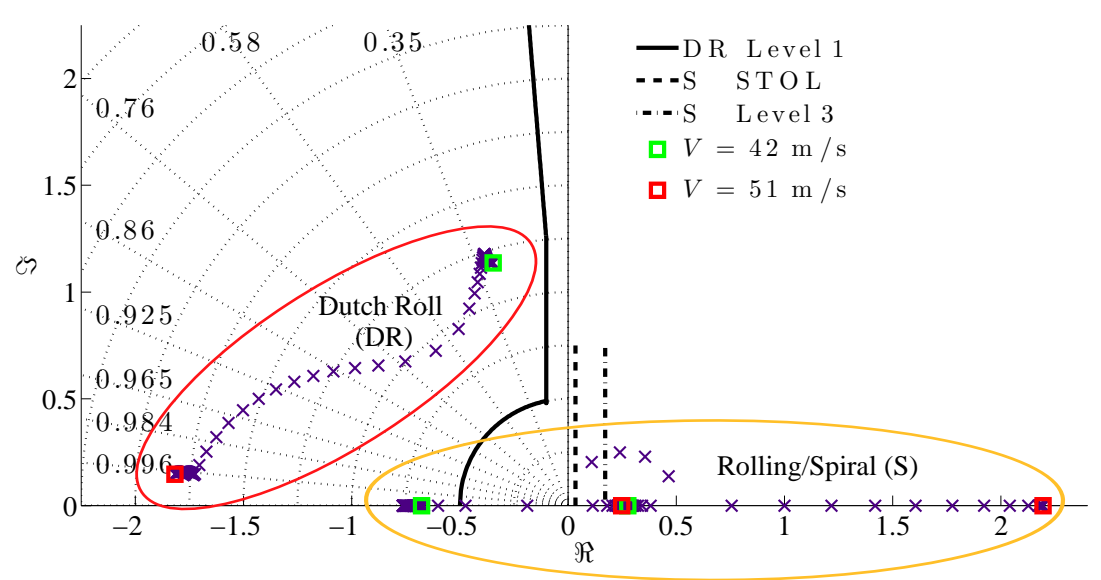

(b) Lateral Motion $\beta=0^{\circ}$

Fig. 12 Poles for a speed variation of $V=42 \mathbf{m} / \mathbf{s}-51 \mathbf{m} / \mathbf{s}$ at an altitude of $A l t=300 \mathbf{m}$

be observed for the aperdiodic spiral and rolling motion. At low airspeed (green boxes on the abscissa) the systems roots indicate an unstable spiral motion (on the right side from the spiral boundaries), which does not even fulfill Level 3 handling qualities, and a stable rolling motion (positive value). The situation deteriorates with increasing airspeed as the roots move towards each other and combine to a temporary interference of rolling motion and spiral motion, which creates complex conjugate roots indicating an unstable oscillation. Finally, an unstable high dynamic root appears at the highest airspeed (red boxes) and the other root is located in a lower but still unstable region as well close to the origin.

Another investigation has been performed, focusing on the root movement during a sideslip variation at an Altitude of Alt $=0 \mathrm{~m}$ with the lowest acceptable approach speed of $V=44 \mathrm{~m} / \mathrm{s} \equiv 85.5 \mathrm{kts}$. This is comparable to an approach situation close to the ground flying with a crab angle due to strong crosswinds. Large sideslip angles can appear due to a decrab maneuver to align the aircraft with the runway center-line. For such sideslip variations the system cannot be divided in lateral and longitudinal subsystems, due to unsymmetrical coupling effects. Figure 13 shows the roots for 
the full aircraft motion for a sideslip variation from $\beta=0^{\circ}$ to $\beta=15^{\circ}$. The roots for the short period and the dutch roll motion show a strong reaction moving towards a turning point, which in this case lies at $\beta=6^{\circ}$. The dutch roll becomes temporarily unstable around this angle. Contrary to that, the spiral root becomes temporarily stable. The

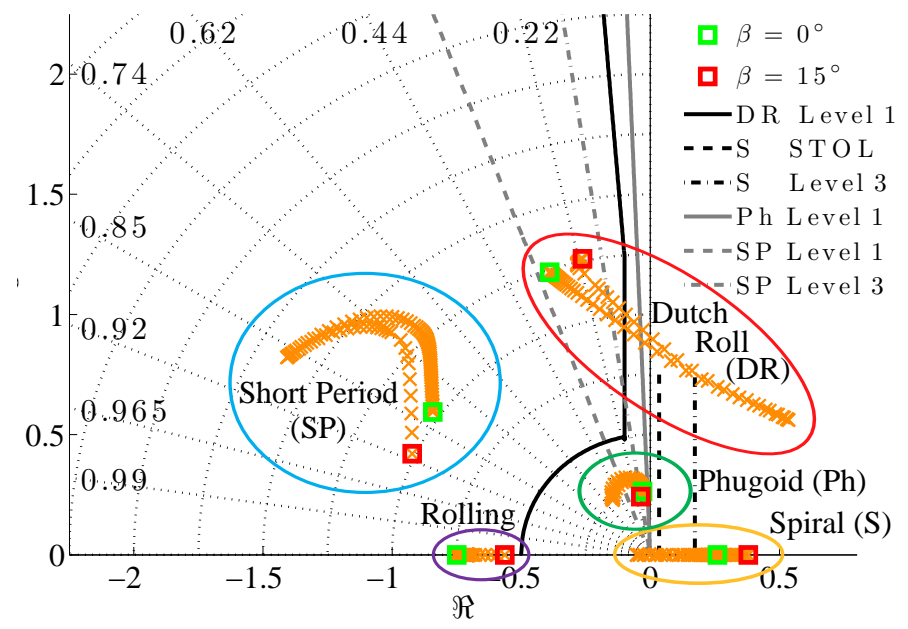

Fig. 13 Poles for a sideslip variation of $\beta=0^{\circ}-15^{\circ}$ at an altitude of $A l t=0 \mathbf{m}$ and $V=44 \mathbf{m} / \mathbf{s}$

root movements show, that a pilot would have to manage completely divergent aircraft reactions due to airspeed or sideslip angle variation during approach, often showing even highly unstable behavior. At high airspeed the workload to stabilize the tendency to turn away due to the spiral dynamics is extremely high. For small sideslip angles, which can appear regularly especially during the approach phase, an unstable dutch roll oscillation cannot be accepted, at all. However, due to the linearization the roots are only valid for the very specific operation point. The results do not indicate, how the aircraft would finally react in a non-linear dynamic simulation in time-domain.

Therefore, full six degrees of freedom flight dynamic simulations have been performed. Figure 14 gives an example for an aircraft response to a rapidly arising $90^{\circ}$-crosswind of $v_{W}=-20 \mathrm{kts}=-10.29 \mathrm{~m} / \mathrm{s}$ leading to instant positive bank angles. Besides the altitude $(A l t)$, airspeed $\left(V_{T A S}\right)$ and flightpath angle $(\gamma)$, the rotational rates around the aircraft's $\mathrm{X}$-, Y- and Z-axis $(p, q, r)$, as well as the corresponding attitude angles $(\Phi, \Theta, \Psi)$ are depicted. The track angle $\chi$ is added to the graph of the heading angle $\Psi$. Additionally, AoA $(\alpha)$, sideslip angle $(\beta)$ and the thrust per engine $(T)$ are given too. The aircraft is trimmed for an unaccelerated horizontal flight at three different airspeeds. The resulting trim values are given in Table 2 For such low airspeeds the crosswind initially generates at least sideslip angles above $\beta>10^{\circ}$.

Table 2 Trim Values

\begin{tabular}{ccccc}
\hline & $V_{T A S}$ & $\alpha$ & Total Thrust & Engine Powersetting \\
\hline $44 \mathrm{~m} / \mathrm{s}$ & $(84.3 \mathrm{kts})$ & $5.6^{\circ}$ & $82.326 \mathrm{kN}$ & $45.22 \%$ \\
$50 \mathrm{~m} / \mathrm{s}$ & $(95.8 \mathrm{kts})$ & $-2.3^{\circ}$ & $70.889 \mathrm{kN}$ & $39.35 \%$ \\
$55 \mathrm{~m} / \mathrm{s}$ & $(105.39 \mathrm{kts})$ & $-7.5^{\circ}$ & $65.954 \mathrm{kN}$ & $37.62 \%$ \\
\hline
\end{tabular}

The instant reaction of the aircraft is consequently strong, but diverges for different airspeeds. Even though, none of the cases show acceptable flight characteristics, the time histories and especially the possibility to have a close look at the 
participating moment generators can reveal the key factors for the resulting aircraft motion. Therefore, several critical points in time are marked by letters (a to d) and will be discussed, based on the related partial moment histories. In each case the aircraft shows strong reactions on the wind perturbation and starts to climb while the airspeed drops. As could be expected due to sideslip influence on the pitching moment, the longitudinal motion is heavily excited. For low airspeed this leads to high angles of attack and ends in irregular attitudes and excessive roll rates. Figure 15 gives the portions for the low speed case. The moments act on the predefined reference point RP25 which is located on the aircraft's center-line at the quarter-chord position of the wing root. Within the model the moments are transformed to the center of gravity. Therefore, the pitching moments are given as deviation values to the initially trimmed state. The second part of the figure (15b) divides the moments due to sideslip further and attributes them to their generating components. The most critical point for the low-speed case is a). At that time the aircraft begins to turn towards the wind direction. The initial yawing moment in total, as well as the sideslip induced portion are positive for the positive sideslip angle and thus act directionally stabilizing. However, this motion comes along with strong pitch-up rates due to the slipstream effects, indicated by the main pitch influence of the fuselage. The rates reach their maximum values at point $b$ ). Meanwhile the exciting moments reduced almost to zero. The yawing moment due to sideslip is mainly counteracted by the yaw damping $C_{n, r}$. However, this leads to almost constant rotational rates, which remain in their excited state. Hence, an ongoing increase of the attitude angles occurs. Finally, the AoA reaches to large values. The aircraft stalls and turns aside at point d). For the rolling motion the most driving moment comes from the yaw-roll coupling term $C_{l, r}$. This cross coupling becomes important, as it correlates with the aircraft's lift coefficient, which is deliberately pushed to high values for STOL aircraft[27]. The rolling moment results from the different velocities at both sides of the wing due to the yaw rate. The coupling increases with decreasing airspeed, since the ratio between the rotational and translational velocity components increases. In addition the large VTP contributes to the coupling effect. Subsumed, the excitation of severe rotational rates around all three axes, initiated by the strong initial aircraft reaction in conjunction with cross-coupling effects, is not naturally damped enough to prevent excessive attitude angles and ultimately stall. Moreover, the existing directional stability contributed to the occurring rates.

In contrast to that, the medium and high airspeed cases, for which the moment parts are presented in Figure 16 \& Figure 17, give a different picture. Since the same dynamic principles but with different impact appear for both cases the analysis will be done exemplary for the medium speed case. This case includes additional model variance due to the achieved AoA values in the model transition range. The instant reaction on the crosswind is to turn left due to the fuselage effect and thus away from the disturbance, increasing the sideslip before point a) is reached. Between point a) and b) the VTP regains its stabilizing effect and counteracts the strong fuselage moments. The yawing moment changes its direction shortly behind point $b$ ). A similar occurrence can be observed for the pitching moment, where the fuselage part dominates the pitching moment coming from the sideslipping motion until point a) is reached. The build up moment is impeded by the HTP. The pitch damping due to the occurring pitch rate $q$ is one of the major reactions, 

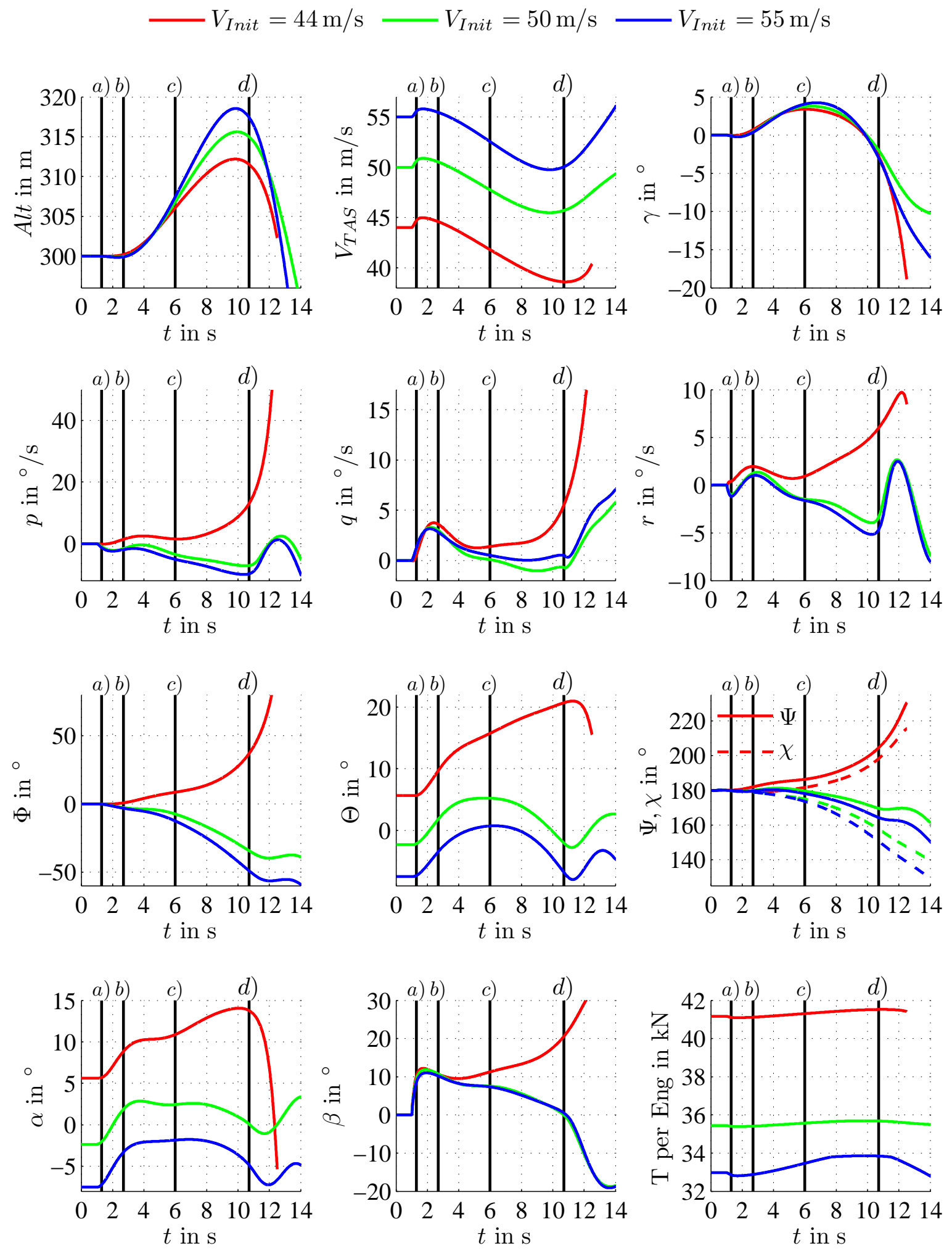

Fig. 14 Aircraft reaction on a $90^{\circ}$-crosswind of $v_{W}=20 \mathrm{kts}$ at $t=1 \mathrm{~s}$ 

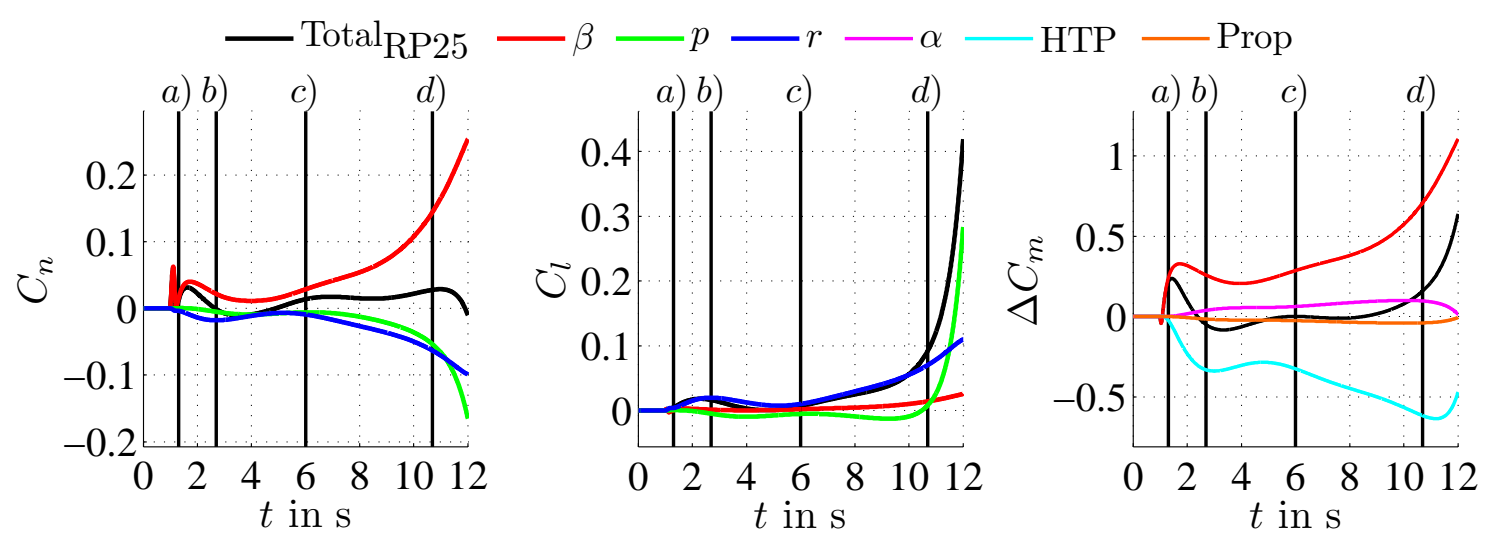

(a) Main influencing moment portions
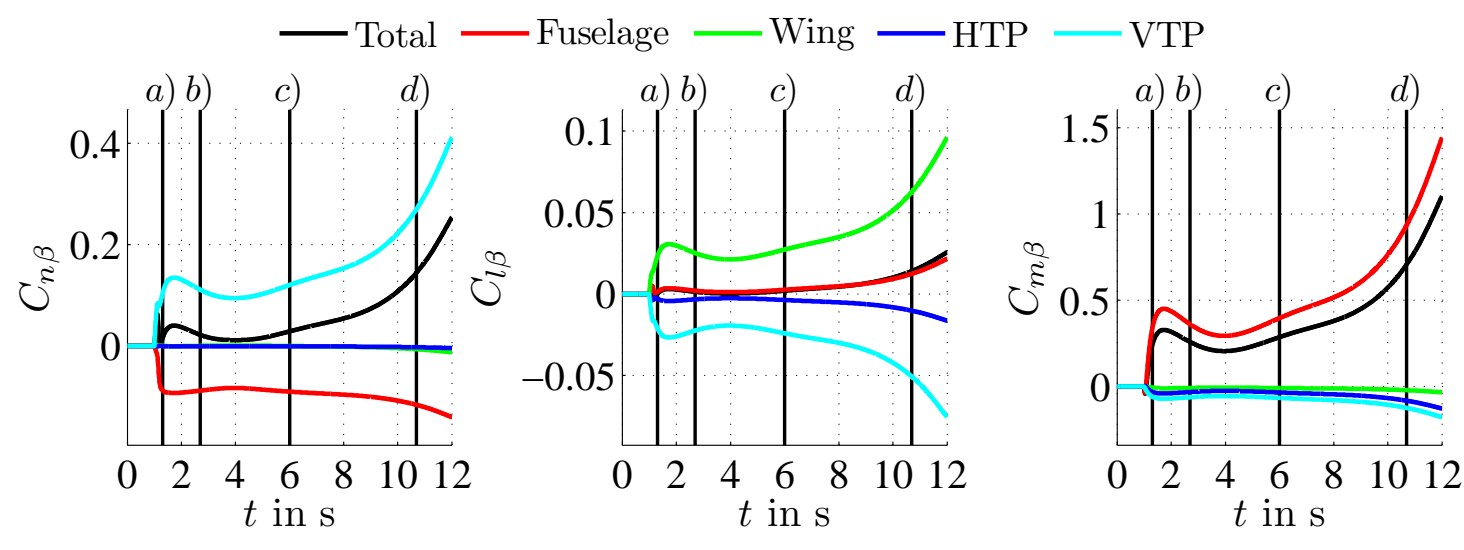

(b) Sideslip influences

Fig. 15 Moment Partials for $V_{T A S}=44 \mathrm{~m} / \mathrm{s}$

reflected by the pitching moment coming from the HTP $C_{m, H T P}$. The delayed onset of damping moments is due to the transport delay $\tau$ of changes in flow and thus wing downwash to reach the HTP. Meanwhile, the aircraft starts to constantly roll aside, initiated by the sideslip, too. At point b) positive rolling moments and thereby accelerations appear mainly driven by the yawing rate $C_{l, r}$. They reduce the roll rate to almost zero so that the aircraft maintains the current bank angle a second later on.

Between point $b$ ) and c) the aircraft motion slightly settles and converges towards a nearly balanced or constant state in terms of AoA, sideslip angle, bank angle and pitch attitude. It has to be noted, that the graphs for the yawing moment in Figure 11, show a zero crossing with a positive gradient around $\beta= \pm 10^{\circ}$ suggesting that the aircraft might find an equilibrium at this state, rather than at $\beta=0^{\circ}$. This characteristic can be described as an excentric directional-stability around these angles. Indeed, at $t=3 \mathrm{~s}$, while crossing $\beta=10^{\circ}$, a directional change of the sideslip induced yawing moment occurs, now acting against the tendency to further reduce its sideslip angle. This tendency is counteracted by the rolling and yawing rate induced moments. In the following, the aircraft turns further, with increasing bank angle and roll rates. Due to the other strong cross coupling of the roll rate induced yawing moments $C_{n, p}$ the sideslip angle 


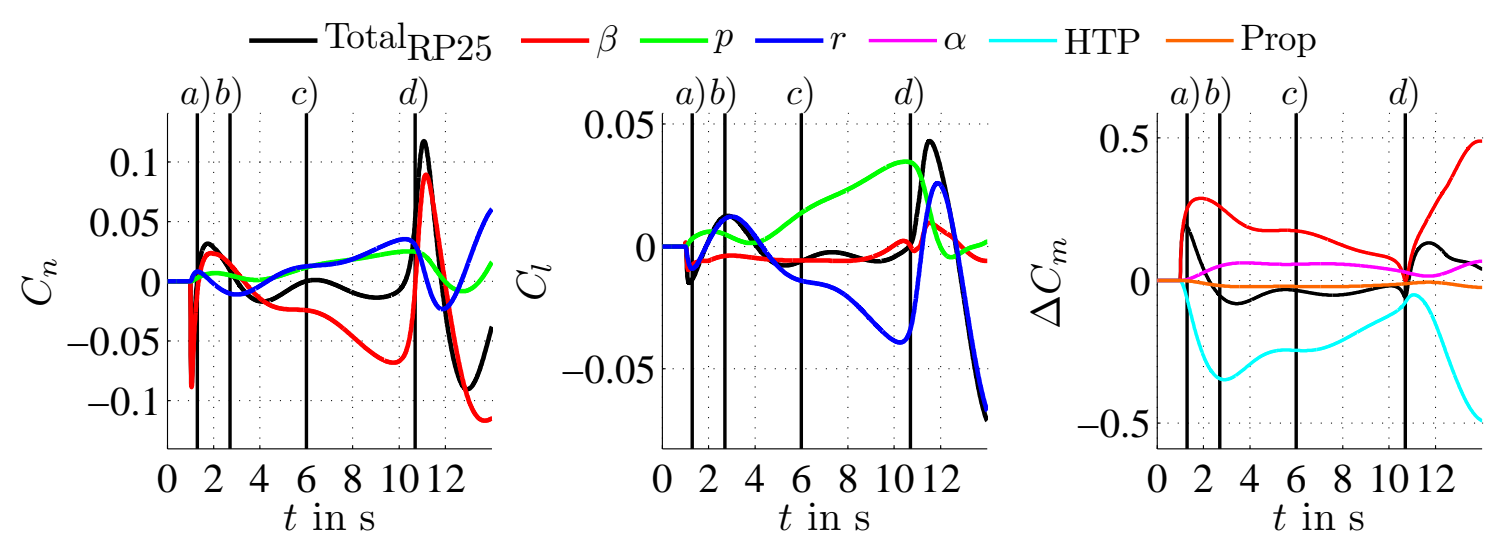

(a) Main influencing moment portions

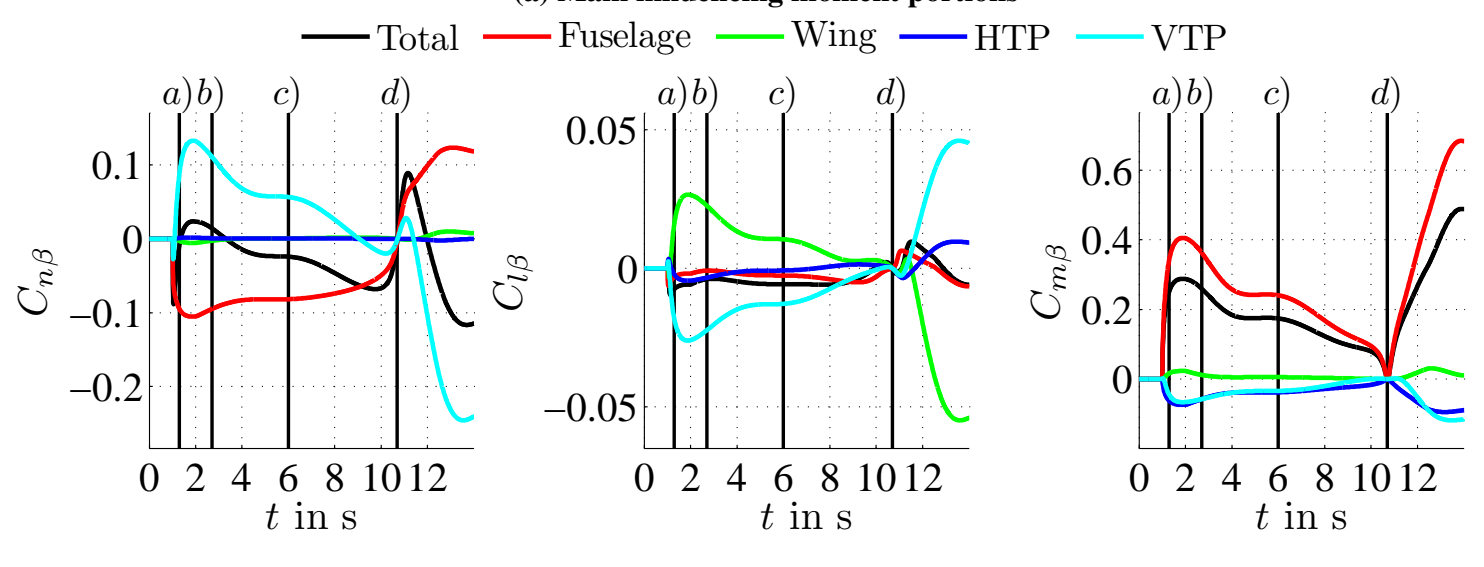

(b) Sideslip influences

Fig. 16 Moment Partials for $V_{T A S}=50 \mathrm{~m} / \mathrm{s}$

is more and more reduced. The near-balanced state is left and especially the yaw and roll rates are stimulated again. Instead, the aircraft gains a crab angle indicated by the divergence of the track $\chi$ and heading angle $\Psi$. As Figure 11 implies, this reduction of sideslip angle is likely to increases the acting yawing moments until a maximum is reached around $\beta=2^{\circ}-5^{\circ}$. The yawing moment peaks at $t=9.7 \mathrm{~s}$ and $\beta=2.4^{\circ}$. Once the aircraft is forced past this point, the tendency to turn the aircraft towards $\beta=10^{\circ}$ diminishes. When crossing zero sideslip the aircraft is turned towards $\beta=-10^{\circ}$, instead. At point d) a key characteristic of this aircraft due to the excentric directional-stability appears. The aft fuselage and temporarily even the VTP are pulled to the reverse direction, re-initiating strong rotational rates. A high dynamic reaction in yawing and rolling motion can be observed accompanied by a pitch attitude dip and subsequent pitch-up after the zero crossing. The heading quickly diverges from the track, which maintains its smooth and constant turn rate. The bank angle temporarily stabilizes due to the yaw rate induced rolling moment. Ultimately, these high dynamics result in an overshoot of sideslip angle and finally the aircraft turns to knife-edge flight (not depicted in the graph). 


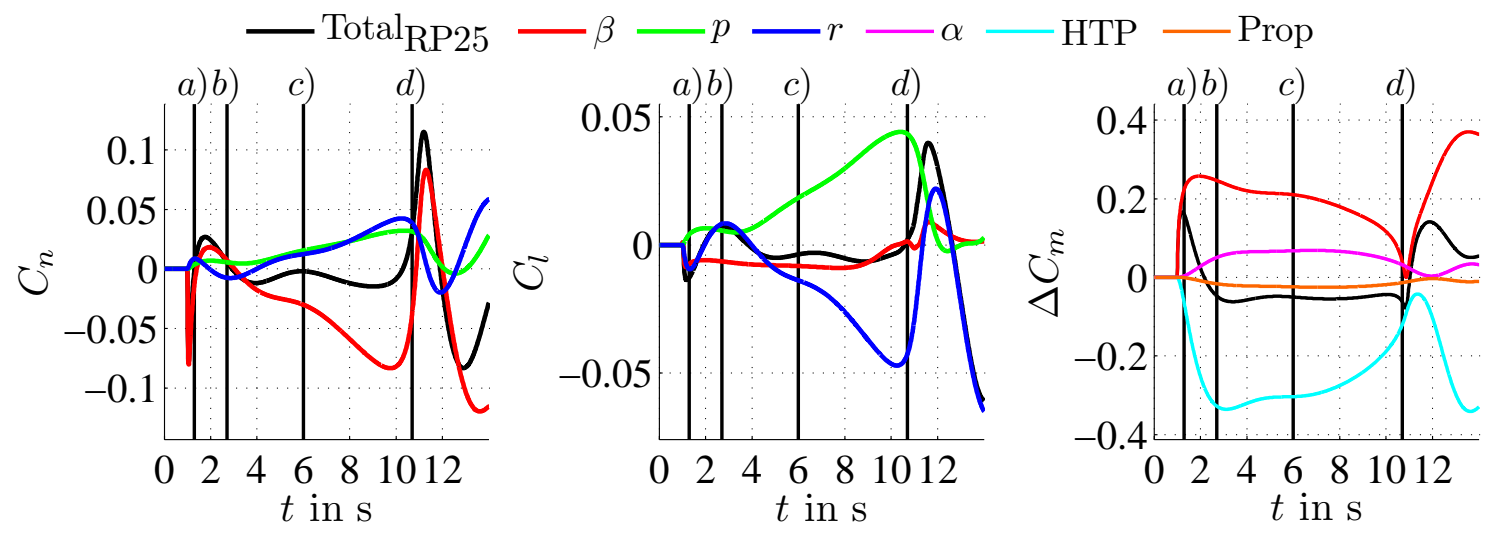

(a) Main influencing moment portions

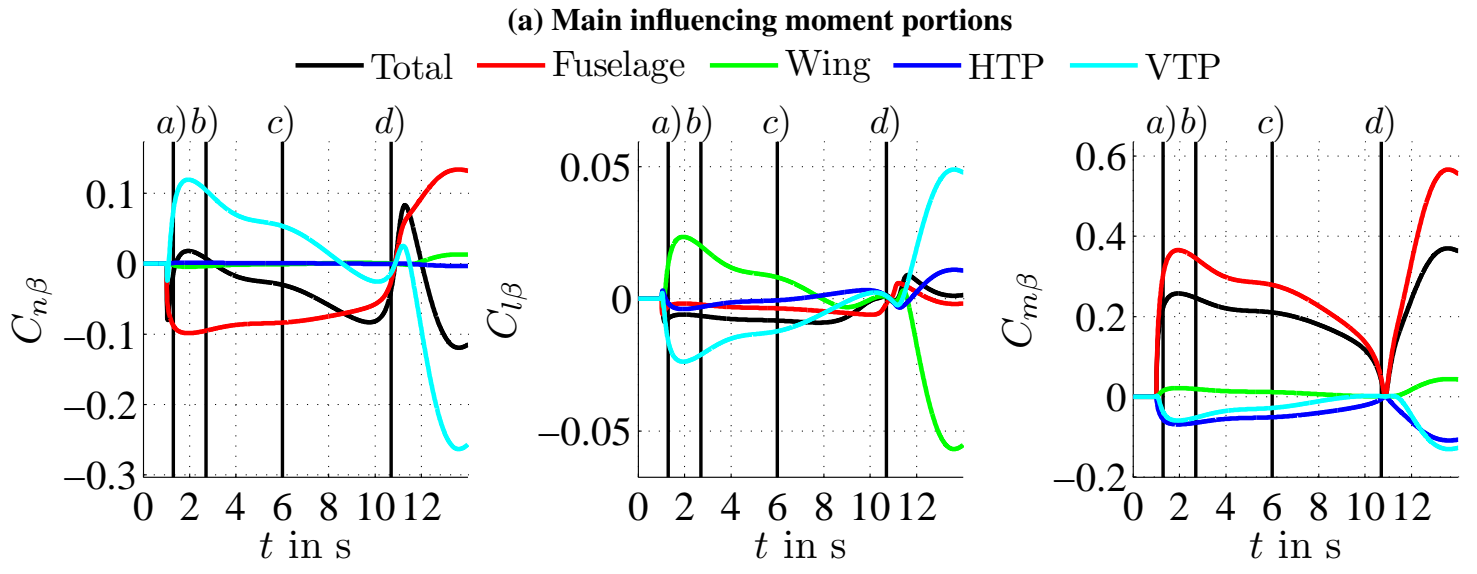

(b) Sideslip influences

Fig. 17 Moment Partials for $V_{T A S}=55 \mathrm{~m} / \mathrm{s}$ 
Even though these reactions are certainly not satisfactory considering aircraft characteristics, they reveal important functional principles of this aircraft. The time histories and yawing moment slopes due to sideslip show, that the aircraft is not generally unstable, but not centering around $\beta=0^{\circ}$. However, the occurring high rates are not sufficiently damped and lead to critical situations without exception. Especially the combination of strong yawing moments and the roll-yaw coupling leads high roll rates and ultimately large bank angles. Essentially, the excentric directional-stability and the involved high moment values due to sideslip act as high gains to the dynamic system, leading to strong excitation and causing unstable and catastrophic behavior.

Nonetheless, there are good chances to remedy the excessive aircraft reaction by simple feedback control laws. Rotational rate dampers and a feedback of the yaw rate to the ailerons might improve the reaction on sideslip forces significantly. As a result, the aircraft would stabilize at $\beta= \pm 10^{\circ}$, if the bank angle is suitably managed. Since a slightly unstable spiral motion is permitted, this task can even be allocated to the pilot. Once having introduced these rate dampers as basic laws, an additional non-linear controller could re-center the sideslip angle equilibrium and create an artificial common linear directional stability. Such a system could also ensure a sufficient order of directional stabilization for satisfactory turn characteristics, being often criticized as poor for STOL aircraft.

In comparison to previous similar configurations, like for example the NC-130B "Hercules" prototype, weaknesses in terms of directional stability are already known [6]. However, the severity and manner of the directional behavior of the SFB-aircraft goes beyond these drawbacks. The reasons for this might be found in the number of engines, which concentrates the propulsion in two high energetic slipstreams. Furthermore, the design of the streamlined cruise optimized shape of the aft fuselage contributes to this behavior. Both factors are part of the design process focusing on efficiency aspects to ensure an economical operation as a commercial transport type aircraft.

\section{Summary and Conclusions}

The aerodynamic performance of the investigated active high-lift aircraft configuration in terms of L/D-ratio and the installed engine performance enables the aircraft to perform very steep flight path angles in climb- and descent-flight. The high-lift system's architecture allows to uncouple pitch-attitude, angle of attack and lift, enabling a control system to command a flight path angle at an independent pitch attitude or angle of attack within the presented ranges. However the propulsion with one engine inoperative is not sufficient to achieve the positive climb rates required by the regulation authorities. Adequate flap retraction concepts will be necessary to ensure quick reconfigurations and thus enough climb performance for go-around maneuvers.

The combination of boundary-layer controlled flaps at high deflection angles and the deflected propeller slipstream lead to strong interactions of the slipstream with the aft fuselage. As a result the aircraft shows an excentric directional stability and in the close range around $\beta=0^{\circ}$ the local directional instability excites large rotational rates around all axes. Ultimately, the aircraft tends to excessive reactions to disturbances leading to catastrophic behavior in the presented 
simulations. These flight characteristics in the lateral motion are not acceptable and require further developments to be able to exploit the STOL-capabilities of this configuration.

With the identification of the key factors of the described drawbacks and the detailed knowledge of their dynamic principles, countermeasures can be developed in terms of aerodynamic design and aircraft control schemes. One part of the revision needs to address the aerodynamics in order to eliminate detrimental propeller slipstream attachments to the aft fuselage. On the flight systems side, there is a high potential to improve the flight dynamics by sophisticated and model based control systems. Based on the developed comprehensive flight mechanics models it is possible to design non-linear control concepts in order to achieve acceptable handling qualities preferably without limiting effects on the promising flight performance. This includes simple basic control laws to damp excessive aircraft motion and in a second step to re-center the aircraft's equilibrium sideslip angle to $\beta=0^{\circ}$. These improvements are considered to be the key aspects to make this aircraft configuration controllable and predictable for pilots, while the aircraft's extraordinary flight performance can be preserved.

\section{Acknowledgments}

This research is conducted within the framework of the Sonderforschungsbereich 880 (collaborative research center) which is funded by the DFG (German Research Foundation). The work has been supported by CFD results from DLR's Tau code generated by Dennis Keller (Institute of Aerodynamics and Flow Technology (AS), DLR). The reference aircraft design has been developed by Wolfgang Heinze (Institute of Aircraft Design and Lightweight Structures (IFL), TU Braunschweig) with the preliminary aircraft design tool PrADO.

\section{References}

[1] Norton, B., STOL Progenitors: The Technology Path to a Large STOL Transport and the C-17A, American Institute of Aeronautics and Astronautics, Reston, VA, USA, 2002.

[2] Radespiel, R., and Heinze, W., "SFB 880: fundamentals of high-Lift for future commercial aircraft," CEAS Aeronautical Journal, Vol. 47, No. 3, 2014, pp. 239-251. doi:https://doi.org/10.1007/s13272-014-0103-6.

[3] Kauth, F., François, D. G., Sayed, Y. E., Semaan, R., Behr, C., Schwerter, M., Leester-Schädel, M., Srinivas, V., Nolte, F., Narjes, G., Müller, J., Atalayer, C., Giesecke, D., Müller, T., Radespiel, R., and Seume, J. R., "Progress in Efficient Active High-Lift," AIAA AVIATION Forum - 35th AIAA Applied Aerodynamics Conference, AIAA, 2017. doi:https://doi.org/10.2514/6.2017-3559.

[4] Delfs, J., Appel, C., Bernicke, P., Blech, C., Blinstrub, J., Heykena, C., Kumar, P., Kutscher, K., Lippitz, N., Rossian, L., Savoni, L., and Lummer, M., "Aircraft and technology for low noise short take-off and landing," AIAA AVIATION Forum - 35th AIAA Applied Aerodynamics Conference, AIAA, 2017. doi:https://doi.org/10.2514/6.2017-3558.

[5] Horst, P., Sommerwerk, K., Keller, D., Diekmann, J. H., Neuert, N., Krukow, I., and Rang, J., "Flight Dynamics Investigation 
of an Active High-Lift Aircraft," AIAA AVIATION Forum - 35th AIAA Applied Aerodynamics Conference, AIAA, 2017. doi:https://doi.org/10.2514/6.2017-3560.

[6] Quigley, H. C., and Innis, R. C., "HANDLING QUALITIES AND OPERATIONAL PROBLEMS OF A LARGE FOURPROPELLER STOL AIRPLANE,” Technical Note D-1647, NASA, Jan. 1963.

[7] Holzhauser, C. A., Innis, R. C., and Vomaske, R. F., “A FLIGHT AND SIMULATOR STUDY OF THE HANDLING QUALITIES OF A DEFLECTED SLIPSTREAM STOL SEAPLANE HAVING FOUR PROPELLERS AND BOUNDARYLAYER CONTROL,” Technical Note D-2966, NASA, 1965.

[8] Burnazzi, M., and Radespiel, R., "Synergies between suction and blowing for active high-lift flaps," CEAS Aeronautical Journal, Vol. 6, No. 2, 2015, pp. 305 - 318. doi:https://doi.org/10.1007/s13272-014-0146-8.

[9] Burnazzi, M., and Radespiel, R., “Assessment of leading-edge devices for stall delay on an airfoil with active circulation control," CEAS Aeronautical Journal, Vol. 5, No. 4, 2014, pp. 359-385. doi:https://doi.org/10.1007/s13272-014-0112-5.

[10] Keller, D., and Rudnik, R., "Integration Aspects of Lift Augmentation Systems on the Aerodynamics of a High-Lift Configuration," SFB 880 - Fundamentals of high-lift for future commertial aircraft, Biennial Report, edited by R. Radespiel and R. Semaan, TU Braunschweig - Campus Forschungsflughafen, Braunschweig, 2015, pp. 145-156.

[11] Teichel, S., Dörbaum, M., Misir, O., Merkert, A., Mertens, A., Seume, J. R., and Ponick, B., "Design considerations for the components of electrically powered active high-lift systems in civil aircraft," CEAS Aeronautical Journal, Vol. 6, No. 4, 2014, pp. 49 - 67. doi:http://dx.doi.org/10.1007/s13272-014-0124-1.

[12] Weiberg, J. A., and Page, V. R., "LARGE-SCALE WIND-TUNNEL TESTS OF AN AIRPLANE MODEL WITH AN UNSWEPT, ASPECT-RATIO-10 WING, FOUR PROPELLERS, AND BLOWING FLAPS,” Technical Note D-25, NASA, September 1959.

[13] Hefferley, R. K., Stapleford, R. L., and Rumold, R. C., “AIRWORTHINESS CRITERIA DEVELOPMENT FOR POWEREDLIFT AIRCRAFT,” Contractor Report NASA CR-2791 / FAA-RD-76-195, NASA/FAA, 1977.

[14] Gerhold, T., "Overview of the Hybrid RANS Code TAU," MEGAFLOW - Numerical Flow Simulation for Aircraft Design, Notes on Numerical Fluid Mechanics and Multidisciplinary Design, Vol. 89, edited by N. Kroll and J. Fassbender, Springer Verlag, Berlin Heidelberg, Germany, 2005, pp. 81-92. doi:https://doi.org/10.1007/3-540-32382-1_5.

[15] Keller, D., and Rudnik, R., "Numerical Investigations of Aerodynamic Properties of a Propeller Blown Circulation Control System on a High Wing Aircraft," CEAS Aeronautical Journal, Vol. 7, No. 3, 2016, pp. 441-454. doi:https://doi.org/10.1007/s13272016-0195-2.

[16] Diekmann, J. H., “Analysis of trimmable conditions for a civil aircraft with active high-lift system,” CEAS Aeronautical Journal, Vol. 6, No. 1, 2015, pp. 109 -120. doi:https://doi.org/10.1007/s13272-014-0132-1. 
[17] Diekmann, J. H., and Hahn, K.-U., "Effect of an active high-lift system failure during landing approaches," CEAS Aeronautical Journal, Vol. 6, No. 2, 2015, pp. 181 - 196. doi:https://doi.org/10.1007/s13272-014-0139-7.

[18] Vasista, S., Nolte, F., Monner, H. P., Horst, P., and Burnazzi, M., “Three-dimensional design of a large-displacement morphing wing droop nose device," Journal of Intelligent Material Systems and Structures, 2018. doi:https://doi.org/10.1177/ $1045389 X 18770863$.

[19] Riddle, D. W., Stevens, V. C., and Eppel, J. C., "Quiet Short-Haul Research Aircraft - A Summary of Flight Research Since 1981,” SAE Technical Paper, SAE International, 1987. doi:http://dx.doi.org/10.4271/872315.

[20] Yamato, H., Okada, N., and Bando, T., "Flight test of the Japanese Upper Surface Blowing STOL experimental aircraft ASKA," AIAA Journal of Aircraft, Vol. 28, No. 10, 1991, pp. 630 - 637. doi:https://doi.org/10.2514/3.46075.

[21] EASA, "Certification Specification and Acceptable Means of Compliance for Large Aeroplanes CS-25," Tech. Rep. Amendment 13, European Aviation Safety Agency, Jun. 2013.

[22] Mori, M., Hayashi, Y., Takasaki, N., and Tsujimoto, T., "QUIET STOL RESEARCH AIRCRAFT ASUKA - DEVELOPMENT AND FLIGHT TEST," International Congress of the Aeronautical Sciences, International Council of Aeronatical Sciences, Stockholm, 1990.

[23] Stephenson, J. D., Jeske, J. A., and Hardy, G. H., "Lateral- Directional Stability and Control Characteristics of the Quiet Short-Haul Research Aircraft (QSRA),” Technical Memorandum 102250, NASA, Moffett Field, California, may 1990.

[24] MIL-HDBK-1797A, “FLYING QUALITIES OF PILOTED AIRCRAFT,” Military handbook, Department of Defense, 1997.

[25] Anderson, S. B., Chinn, H. W., Filisetti, A., Hafer, X., McGregor, D. M., Schroers, L. G., and Ville, G., "V/STOL Handling," Report AGARD-R-577-70, Advisory Group for Aerospace Research \& Development, NATO, 1970.

[26] Allison, R., Mack, M., and Rumsey, P., "DESIGN EVALUATION CRITERIA FOR COMMERCIAL STOL TRANSPORTS," Contractor Report 114 454, NASA, 1972.

[27] Etkin, B., Dynamics of Atmospheric Flight, $1^{\text {st }}$ ed., John Wiley \& Sons, Inc., 1972. 